\title{
Etiology of lumbar lordosis and its pathophysiology: a review of the evolution of lumbar lordosis, and the mechanics and biology of lumbar degeneration
}

\author{
Carolyn J. Sparrey, Ph.D., ${ }^{1}$ Jeannie F. Bailey, M.A., ${ }^{2}$ Michael Safaee, B.S., ${ }^{3}$ \\ Aaron J. Clark, M.D., Ph.D., ${ }^{3}$ Virginie Lafage, Ph.D., ${ }^{4}$ Frank Schwab, M.D., 4 \\ Justin S. Smith, M.D., Ph.D., 5 and Christopher P. Ames, M.D. ${ }^{3}$ \\ ${ }^{I}$ Mechatronic Systems Engineering, Simon Fraser University, Surrey, British Columbia, Canada; \\ ${ }^{2}$ Departments of Anthropology and Orthopaedics \& Sports Medicine, University of Washington, Seattle, \\ Washington; ${ }^{3}$ Department of Neurological Surgery, University of California San Francisco, California; \\ ${ }^{4}$ Department of Orthopaedic Surgery, NYU Hospital for Joint Diseases, New York, New York; and \\ ${ }^{5}$ Department of Neurosurgery, University of Virginia Health System, Charlottesville, Virginia
}

\begin{abstract}
The goal of this review is to discuss the mechanisms of postural degeneration, particularly the loss of lumbar lordosis commonly observed in the elderly in the context of evolution, mechanical, and biological studies of the human spine and to synthesize recent research findings to clinical management of postural malalignment. Lumbar lordosis is unique to the human spine and is necessary to facilitate our upright posture. However, decreased lumbar lordosis and increased thoracic kyphosis are hallmarks of an aging human spinal column. The unique upright posture and lordotic lumbar curvature of the human spine suggest that an understanding of the evolution of the human spinal column, and the unique anatomical features that support lumbar lordosis may provide insight into spine health and degeneration. Considering evolution of the skeleton in isolation from other scientific studies provides a limited picture for clinicians. The evolution and development of human lumbar lordosis highlight the interdependence of pelvic structure and lumbar lordosis. Studies of fossils of human lineage demonstrate a convergence on the degree of lumbar lordosis and the number of lumbar vertebrae in modern Homo sapiens. Evolution and spine mechanics research show that lumbar lordosis is dictated by pelvic incidence, spinal musculature, vertebral wedging, and disc health. The evolution, mechanics, and biology research all point to the importance of spinal posture and flexibility in supporting optimal health. However, surgical management of postural deformity has focused on restoring posture at the expense of flexibility. It is possible that the need for complex and costly spinal fixation can be eliminated by developing tools for early identification of patients at risk for postural deformities through patient history (genetics, mechanics, and environmental exposure) and tracking postural changes over time.
\end{abstract} (http://thejns.org/doi/abs/10.3171/2014.1.FOCUS13551)

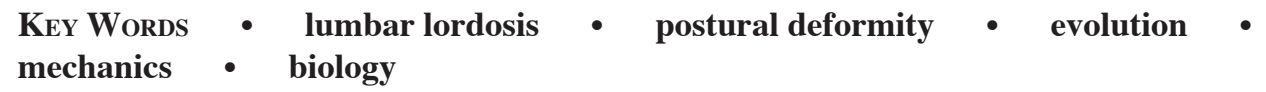

\section{$\mathrm{L}$} UMBAR lordosis is unique to the human spine and is necessary to facilitate our upright posture. However, decreased lumbar lordosis and increased thoracic kyphosis are hallmarks of an aging human spinal column. ${ }^{75,143}$ Degeneration of the sagittal spine curvature leads to loss of sagittal alignment, which is implicated in a broad range of adverse health outcomes. ${ }^{67}$ Significant postural degeneration often requires surgical intervention to alleviate pain and facilitate upright posture and ambulation. However, surgical interventions to correct postural deformities are costly and complicated and include a risk of neurological deficits. The unique upright posture and

\footnotetext{
Abbreviations used in this paper: $\mathrm{LL}=$ lumbar lordosis; mya $=$ million years ago; $\mathrm{PI}=$ pelvic incidence; $\mathrm{ROM}=$ range of motion; SVA = sagittal vertical axis.
}

lordotic lumbar curvature of the human spine suggest that an understanding of the evolution of the human spinal column and the unique anatomical features that support lumbar lordosis may provide insight into spine health and degeneration.

Evolutionary medicine is being touted as a more holistic way to understand and treat conditions of the human body. ${ }^{55,206}$ While this approach is primarily targeted toward understanding drug therapies and genetics, the approach is also valuable for understanding age- and disease-related degenerative changes to the body structure. Considering evolution of the skeleton in isolation from other scientific studies provides a limited picture for clinicians. Conducting a review of the evolution of lumbar lordosis within the context of recent findings in spine mechanics and the biology of spinal structures will help to 


\section{J. Sparrey et al.}

influence our clinical management of lumbar pathophysiology and suggest effective pathways for intervention.

The goal of this review is to discuss the mechanisms of postural degeneration, particularly the loss of lumbar lordosis commonly observed in the elderly in the context of evolution, mechanical, and biological studies of the human spine and synthesize recent research findings to our clinical management of postural malalignment. Degenerative conditions in the lumbar spine have been attributed to the overuse, ${ }^{186}$ underuse, ${ }^{184}$ and misuse ${ }^{123}$ of the spine as well as being identified as an evolutionary "mismatch" (between our evolved selves and our current lifestyle). ${ }^{60,113,116}$ Understanding the evolution of lumbar lordosis and the anatomical features that facilitate lordosis in hominins, both extant and extinct, may assist in determining optimal uses of the spine and identify opportunities to reduce degenerative changes. Reviewing these evolutionary theories in the context of spine mechanics and biology will provide unique insights into postural degeneration that should highlight opportunities for clinical intervention.

\section{Evolution of Lumbar Lordosis With Habitual Bipedalism}

Extensive research has examined the origins of our habitual bipedalism by looking into the fossil record and noting significant morphological changes necessary to support upright posture. A key challenge in mapping the progress of evolution is the limited number of specimens and the poor condition of most samples. Unlike medical research where statistical significance is critical for conclusions, the foundation of evolution research is the development of theories or hypotheses based on scant physical artifacts. We provide a very brief summary of lumbar spines within the fossil record and the morphological trends in lumbar spine curvature that begins from a presumably generalized nonlordotic lumbar spine of a last common ancestor with chimpanzees to the fully lordotic lumbar spines of modern humans.

The divergence between extant apes occurred 5-11 million years ago (mya) between Homo and Pan (includes chimpanzees and bonobos). ${ }^{177}$ Although morphologically and genetically similar to humans, extant great apes are orthograde quadrupeds that demonstrate a unique "knuckle walking" locomotion and are capable of limited durations of bipedality. Despite many structural similarities in the spinal columns and vertebrae, the great apes' lumbar spines lack a lordotic curve typical of humans. The flat lumbar spines of the great apes are also much stiffer than human spines and offer limited mobility. ${ }^{116}$ Understanding the functional limitations of a flattened lumbar spine, typical in the great apes, may provide insight into the effects of degeneration lumbar flattening in elderly humans.

Habitual bipedalism is currently shown to date back to Ardipithecus ramidus (4.4 mya) with morphological features indicative of bipedalism, such as an acute greater sciatic notch and a facultative medial longitudinal arch of the foot. ${ }^{118}$ Older potential hominin bipeds include
Orrorin tugenensis from Tugen Hills, Kenya, at roughly 5.8-6.1 mya ${ }^{175}$ and Sahelanthropus tchadensis from South Sahel, Chad, at 6-7 mya; ${ }^{39}$ however, fossil evidence for lumbar morphology is scarce due to the porous and largely trabecular composition of lumbar vertebral bodies. The earliest lumbar spines include partial spines from Australopithecus africanus (Sts 14; Stw 431) ${ }^{157,189}$ at 2.5-3 mya, Australopithecus sediba (MH1 and MH2) at 1.977 mya, 207 and Homo erectus (KNM-WT 15000, "Turkana boy") at 1.5 mya. ${ }^{38}$ There is debate about the number of lumbar vertebrae in australopithecines. Some analysis of the partial spines suggest 6 lumbar vertebrae, ${ }^{117,157}$ while other reviews indicate 5 lumbar vertebrae, when counting from the last rib-bearing vertebra, similar to modern humans. ${ }^{73,74,207}$ The one $H$. erectus juvenile is also thought to have 5 lumbar vertebrae. ${ }^{73,74}$ All of these early partial lumbar spines demonstrate a variably mild degree of lordosis, based on the amount of wedging on the posterior boarder of the lumbar vertebral bodies. ${ }^{44,107,157,200,204,207}$

Estimates of the degrees of lumbar lordosis in hominin ancestors have been difficult to obtain because of the absence of the intervertebral discs and the lack of complete spine specimens. A new method for calculating the lordotic angle based on the orientation of the inferior articular process explained $89 \%$ of the variation in lordotic curvature in humans and primates. ${ }^{21}$ Applying this method to the spines of extinct hominins showed the lordotic angles of australopithecines $\left(41^{\circ} \pm 4^{\circ}\right), H$. erectus $\left(45^{\circ}\right)$, and fossil Homo sapiens $\left(54^{\circ} \pm 14^{\circ}\right)$ were similar to modern humans $\left(51^{\circ} \pm 11^{\circ}\right)$, while modern nonhuman apes had smaller lordotic angles $\left(22^{\circ} \pm 3^{\circ}\right)$ than humans..$^{24}$ Interestingly, despite being contemporary with $H$. sapiens, Homo neanderthalensis showed significantly smaller lordotic angles $\left(29^{\circ} \pm 4^{\circ}\right)$ than humans, which may suggest differences in Neandertal posture and locomotion from that of modern humans. ${ }^{24}$

Considering the close genetic relationship and anatomical similarities between Neandertals and humans, it is quite surprising that the lumbar spine of Neandertals is hypolordotic. The lumbar lordosis of early genus Homo falls between the lesser lordosis of Neandertal and greater lordosis of humans. ${ }^{24}$ The reduced form of lordosis in the Neandertal spine is attributed to an anterior wedging of the lumbar vertebral bodies. . $^{21,202}$ The functional reason for the reduced lordosis of the Neandertal lumbar spine is unclear; however, it may provide a mechanical benefit for locomotion in sloped terrain. Neandertals are thought to have spent significant time on sloped, mountainous terrain in Eurasia, ${ }^{84}$ and gait studies on modern humans demonstrate a significant lumbar flattening during uphill walking. ${ }^{110,111,197}$

\section{Structural Evolution in the Lumbar Spine}

The distinct lordotic curve of the human lumbar spine is created by wedging of both the lumbar intervertebral discs and the vertebral bodies. A study by Been et al. ${ }^{22}$ measured the relative contributions of vertebral and disc wedging on lordotic curves in humans and pronograde primates (macaques). On average, approximately $10 \%$ of the lumbar curve is contributed by wedging of 
the vertebral bodies $\left(5^{\circ}\right)$, while the remaining $90 \%\left(46^{\circ}\right)$ is due to wedging of the discs. In contrast, macaque vertebral body wedging in the lumbar spine opposes lumbar lordosis. The average lordotic curve in a macaque is $15^{\circ}$ while the wedging of the vertebral bodies contributed $25^{\circ}$ of kyphosis. The lumbar discs in the macaques, however, showed similar lordotic wedging as seen in the human spines $\left(40^{\circ}\right.$ vs $\left.46^{\circ}\right)$. These results suggest that the evolution from pronograde to orthograde posture resulted mainly from an increase in the vertebral body wedging and emphasize the important contribution of discs in maintaining lumbar lordosis. The evolution of lumbar lordosis to the degree at which it is seen in modern humans occurred in parallel with other skeletal changes such as limb lengthening, ${ }^{10,154,155}$ pelvic restructuring ${ }^{116,162}$ thoracal invagination of the spine, ${ }^{116}$ and reorganization of the spinal musculature to support bipedal motion.

Changes to the curvature of the lumbar spine also required adaptations within the spinal musculature, including migration of key muscle attachments on the vertebral body and the spinopelvic structure. A comprehensive review of the fossil records revealed two important structural changes to the lumbar vertebrae. ${ }^{60}$ The first change was the posterior shift of the lumbar transverse processes from the vertebral body, as they continue to be in Old World Monkeys, to the neural arch, though the timing of migration is debated. ${ }^{160}$ The shift of the transverse processes allowed the longissimus muscles to become major lateral flexor and extension muscles of the spine, necessary for rotating the pelvis and maintaining balance during bipedal walking, ${ }^{60}$ and limited the role of the erector spinae muscles to resisting forward flexion. ${ }^{166}$ The second change was the loss of the styloid processes. The loss of the styloid processes facilitated a larger range of motion (ROM) in the hominin spine, allowing for adoption of a variety of postures. Later changes to the spinopelvic structure included a widening of the sacrum and ilia and a progressive cranial to caudal widening of the lumbar vertebrae. ${ }^{116}$ The structural changes to the vertebrae preceded changes in musculature in the spine. The migration of the insertion points of the iliocostalis lumborum muscles to the iliac crests, necessary for spine stabilization and rotation, occurred 15-18 mya. ${ }^{60}$ The posterior migration of the posterior superior iliac spine (1-2 mya) combined with the iliocostaslis lumborum migration facilitate modern human lumbar lordosis. ${ }^{60}$

The connection between the sacrum and the pelvis provides the anchor point for the lumbar spine and a means to translate the load of the upper body to the pelvis and lower limbs. ${ }^{147}$ Simultaneous to changes in the vertebrae and back musculature during evolution, there were significant changes in the pelvis. These changes in the pelvis supported upright posture and efficient bipedal motion as well as increasing the diameter of the birth canal. A recent study of human, hominin, and hominoid pelves was the first to characterize changes in pelvic incidence throughout evolution. ${ }^{28}$ Pelvic incidence (PI) is a fixed clinical measure of sacral orientation in the pelvis (Fig. 1). Hominoids in the study included Pan, Gorilla, Pongo, and Hylobates. The PI for hominoids was consistent for all species $\left(27^{\circ} \pm 5^{\circ}\right)$. This was substantially

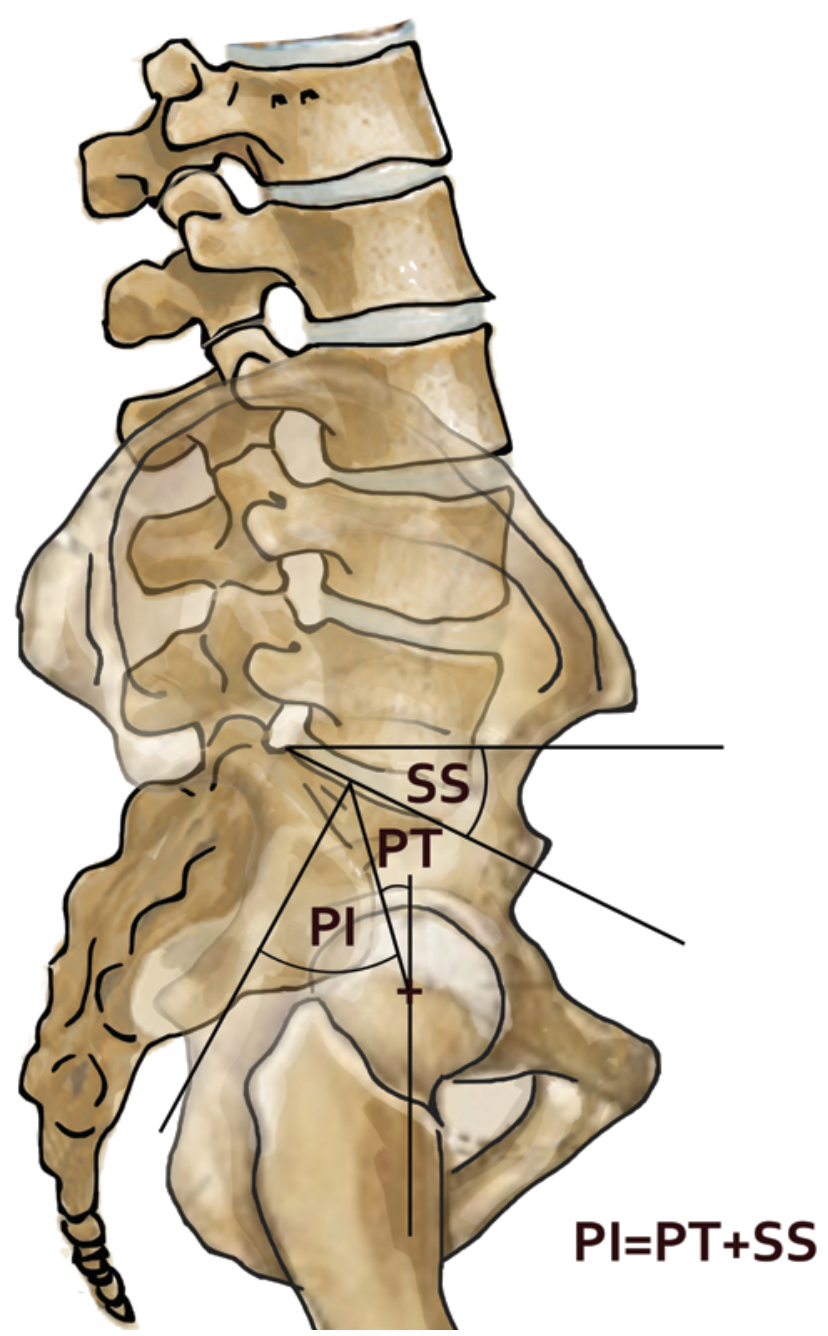

Fig. 1. Illustration showing the standard angles of the spine and pelvis. Pelvic incidence is the angle between a line connecting the center of the sacral plate to the middle axis of the femoral heads and a line perpendicular to the midpoint of the sacral plate. Sacral slope (SS) is the angle between the sacral plate and a horizontal line. Pelvic tilt (PT) is the angle between the line that connects the midpoint of the sacral plate to the middle axis of the femoral heads and a vertical line. Summing PT and SS equals the PI. The PT and SS are oppositely affected by changes in patient stance. However, $\mathrm{PI}$ is a fixed measure, independent of patient stance or posture. Copyright Andrew McNichol. Published with permission.

lower than the PI measured in australopithecines $\left(43.5^{\circ}\right.$ $\left.\pm 2^{\circ}\right)$ and modern humans $\left(54^{\circ} \pm 10^{\circ}\right)$. Interestingly, the PI for Neandertals was similar to hominoids, not modern humans. There was a strong correlation between PI and lumbar lordosis for each group of hominoids, hominins, and modern humans (Table 1). The pelvic structure of australopithecines and Neandertals are wider than current modern humans. The increased sacral angle in modern humans was necessary to enlarge the pelvic outlet to accommodate large fetal heads. ${ }^{200}$ The close correlation between PI and lumbar lordosis is a mechanism for the body to position its center of gravity. However, PI may be compromised between the evolutionary pressures for efficient bipedal motion and the obstetric requirements of modern humans. 


\section{J. Sparrey et al.}

TABLE 1: Pelvic incidence and lumbar lordosis (L1-S1 Cobb angle) in normal adults correlate with each other in hominoids, hominins, and modern humans*

\begin{tabular}{llccc}
\hline \multicolumn{1}{c}{ Authors \& Year } & \multicolumn{1}{c}{ Species } & No. of Samples & Pl (Mean \pm SD) & LL (Mean \pm SD) \\
\hline Been et al., 2013 & hominoids & 19 & $27 \pm 5$ & $22 \pm 3.4$ \\
Been et al., 2013 & Australopithecines & 2 & $43.5 \pm 2$ & $41 \pm 4$ \\
Been et al., 2013 & Neandertal & 3 & 34 & $29 \pm 4$ \\
Been et al., 2013 & modern H. sapiens & 53 & $54 \pm 10$ & $51 \pm 11$ \\
Labelle et al., 2004 & modern H. sapiens & 160 & $52 \pm 5$ & $\mathrm{NA}$ \\
Vialle et al., 2005 & modern H. sapiens & 300 & $56 \pm 10$ & $58.5 \pm 10$ \\
Peleg et al., 2007 & modern H. sapiens & 255 & $55 \pm 13$ & $\mathrm{NA}$ \\
Hong et al., 2010 & modern H. sapiens & 30 & $\mathrm{NA}$ & $39.88 \pm 10.02$ \\
\hline
\end{tabular}

* There is large variation in normal measures of PI and lordosis, which are measured in degrees. LL = lumbar lordosis; NA = not available.

\section{Degeneration of Lordosis: Misuse, Overuse, or Evolutionary Weak Point?}

The human lumbar spine is often labeled the "evolutionary weak point" of the spine and is the most common site of degenerative changes in the vertebrae and intervertebral discs. ${ }^{60}$ Particular focus is given to the human L5-S1 junction as the spinal segment with the greatest individual curvature and the greatest occurrence of degenerative conditions (20\% of the total spine).$^{60}$ Lumbar lordosis is unique to the human spine, which fuels this accusation of evolutionary failure. However, degenerative changes occur with similar frequency in spines of primates in captive populations despite their lack of lumbar lordosis. ${ }^{140}$ In contrast, wild populations of old world primates show a remarkable absence of degeneration. ${ }^{95}$ The challenge of accurately aging wild primates makes it difficult to determine if degenerative spinal conditions in captive populations are a result of longer life spans in captivity or forced changes in lifestyle. Interestingly, captive populations of macaques are reported to spend a significant portion of their waking time sitting, unlike their wild counterparts. ${ }^{140}$

The occurrence of degenerative conditions in human spines motivates the question of whether humans are now outliving their evolved form. Over 3 million years ago the maximal lifespan of our human ancestors was similar to that of great apes, approximately 50 years. ${ }^{79}$ In reality, the average life expectancy was much lower due to high rates of infant and child mortality. The average human lifespan increased dramatically by reducing infant/child mortality and reducing disease and war-related mortality in adults in the Upper Paleolithic era $(30,000$ years ago). ${ }^{42}$ Increased longevity after the cessation of reproduction means that degenerative spine conditions do not factor into direct selection. However, there are theories that support the evolutionary benefits of postreproduction longevity in women. These theories highlight the survival advantages of her children ${ }^{146}$ and grandchildren. ${ }^{78,79,142}$ In addition, evolution models project the current maximal human life span at approximately $100-120$ years. ${ }^{97}$ It therefore seems unlikely that spinal degeneration occurring in patients as young as 30 years is a result of people outliving their evolved design.
The human lumbar spine has adapted its configuration throughout evolution. Skeletons of Australopithecus showed lumbar spines that likely comprised 6 lumbar vertebrae. $117,128,203,207$ In the subsequent course of evolution the human lumbar spine was reduced by 1 vertebra when that vertebra was captured in the pelvic girdle and became part of the sacrum. In a review of the Galloway Osteological Collection (Kampala, Uganda), 4\% of modern humans continue to have a sixth lumbar vertebra. ${ }^{120}$ A classification that looks at the spine as a continuum in humans and extant primates indicates the total number of vertebrae in the thoracolumbosacral spine is consistent, with $81 \%$ of samples having 22 vertebrae, while $19 \%$ of samples had 21 or 23 vertebrae; it is the distribution of vertebrae among the thoracic, lumbar, and sacral regions that is species specific. ${ }^{2}$ In gorillas the lumbar spine evolved to $3(41 \%)$ or $4(38 \%)$ vertebrae, while the thoracic spine has 13-14 vertebrae. ${ }^{2}$ This truncated lumbar spine coupled with long ilia of the pelvis supports the substantial bulk of the gorilla's upper body and effectively shields the lumbar spine from overloading. ${ }^{128}$ The short lumbar spines of great apes are very stiff and have limited flexion. ${ }^{201}$ This differential evolution of human and old world primate lumbar spines suggests a functional purpose for 5 lumbar vertebrae in humans, not an evolutionary failure.

Determining the effect of modern lifestyle on spinal degeneration in humans is difficult. However, several studies examining osteological remains around the globe show a common pattern of osteoarthritis and osteophytosis in the cervical and lumbar spine in specimens dating from 3500 years ago ${ }^{35}$ to postmedieval times 800 years ago, ${ }^{158}$ suggesting that spinal degeneration cannot be solely attributed to the sedentary lifestyle of the average westernized society. In contrast, in Indian tribes with minimal Western influence, elderly tribesmen demonstrated little to no disc degeneration in their spines. ${ }^{59}$ Despite limited disc degeneration, however, there was substantial degeneration in the vertebral bodies similar to the previously cited studies. The study noted that the tribesman rarely stood in a static posture. If not walking the tribesmen would squat (not sit), which is a dynamic posture requiring continuous stabilization. The elderly tribesmen also 
demonstrated slightly less lumbar lordosis than their European counterparts. These observations of spine and disc health within isolated populations motivate discussion of another element of disc and spinal degeneration. Are differences in disc health and longevity observed dictated by lifestyle (mechanical loading) or genetic selection in these different populations? In the subsequent sections we review the recent literature on lumbar spine mechanics and vertebrae and disc biology to further understand degenerative lumbar flattening.

\section{Sexual Dimorphism and the Lumbar Spine}

Accounting for sexual dimorphism is becoming increasingly important and common in many fields of medicine and must also be considered in this discussion of lumbar lordosis. Upright, bipedal posture brings a unique set of challenges to the female spine during pregnancy. The increased fetal load anterior to the spine changes the center of mass of the trunk and could affect ambulation and balance if there was no adaptation of the pregnant mother's stature. A recent study demonstrated a significant increase in lumbar lordosis during pregnancy and a change in load distribution in the lumbar spine to have the zygapophysial joints carry more than double their normal load during pregnancy. ${ }^{204}$ This shift in load distribution is thought to shield the discs from damaging shear loading. Three key structural differences between male and female lumbar spines facilitate this lordotic adaptation. The first is that lordosis attributable to vertebral body wedging is greater in females than in males. ${ }^{126,204}$ Second, female zygapophysial joints are larger relative to vertebral body size (14\%) and more coronally oriented $(13 \%)$ than males. Third, the relative interfacet distance was wider in females than males. ${ }^{126}$ Several other studies have observed the degree of standing lumbar lordosis in the female spine to be 26\%-28\% greater than the male spine; ${ }^{30,139,210}$ however, no information was provided on the parous history of those females. Interestingly, changes in mass distribution in the body due to increased body mass index showed little ${ }^{85,137}$ or no effect on lumbar lordosis in males or females. ${ }^{159,211}$

\section{Development of Lumbar Lordosis}

The physical capacity of the human spine to develop lumbar lordosis is due to evolutionary changes in the spine and pelvis; however, the degree of lumbar lordosis develops through infancy, toddler, and childhood. Human infants show little or no lumbar lordosis in utero, ${ }^{44}$ and the degree of lumbar lordosis coincides with the stages of bipedal activity in modern humans. ${ }^{1}$ Other researchers have demonstrated that the degree of lumbar lordosis continues to increase through childhood. ${ }^{46}$ Lumbar lordosis alone is not sufficient to support the ROMs the human body undergoes on a daily basis; the spine must also be flexible. Lumbar lordosis can be developed (to a lesser extent) in primates trained to walk bipedally from infancy ${ }^{80,151}$ however, the lumbar curve in these primates is fixed and does not have the flexibility of the human spine.

\section{Mechanics of Lumbar Lordosis}

\section{Mechanical Advantage of Lumbar Lordosis}

To understand the potential underlying causes of degeneration it is important to know the functional benefits of lumbar lordosis. Lumbar lordosis is critical for balancing the human body in upright posture. However, lumbar lordosis is not a uniquely human trait. In infants the lumbar spine has only slight lordosis or may have no lordosis at all. The lordotic curve develops with developmental stages of bipedalism. ${ }^{1}$ Infants and toddlers who walk early demonstrate increased lordotic curves while those who walk late or not at all have only slight lordosis. ${ }^{1}$ Japanese macaque monkeys trained from infancy to walk bipedally also demonstrate lumbar lordosis. ${ }^{151}$ The critical distinction between human and primate lumbar spines, however, is the flexibility or ROM in the spine. Macaques' lordosis develops from an increase in the ventral lengths of the vertebral bodies without corresponding variations in spinous process alignment; therefore, they maintain their lumbar lordosis during all activities including sitting. In contrast, humans show a significant flattening of their lumbar spines during relaxed sitting. ${ }^{151}$ While lumbar lordosis is necessary for efficient upright walking, lumbar flattening is equally necessary for other activities. Understanding the influence of lumbar lordosis and lumbar flexibility on human activities is critical for evaluating how to best balance the needs of a patient when determining the most effective approach to correct the curvature of a deformed spine.

The degree of lordosis in the lumbar spine is the main factor that influences the conversion of the extensor power developed by the intrinsic back muscles to axial torsion necessary to rotate the pelvis in walking. Primates without lumbar lordosis who occasionally engage in bipedal walking demonstrate great lateral pelvic movements because of the inability to rotate their pelves. ${ }^{91}$ However, a chimpanzee with forelimb paralysis who adopted a bipedal gait in the wild did show an adaptation to rotate the pelvis during gait. ${ }^{20}$ This change occurred along with a significant decrease in thoracic kyphosis and retraction of the scapula, which moved the center of mass over the pelvis. The rotation of the pelvis during normal human gait comes primarily from flexibility in the lumbar spine. In healthy people, the pelvis rotates an average of $10.4^{\circ}$ during walking, with $8.34^{\circ}$ attributable to lumbar axial rotation..$^{205}$ Lumbar spine flexibility or ROM provides mechanical advantages for sitting, lifting, and bending tasks by changing the distribution of loading in the spine. ${ }^{4}$ In healthy spines the lumbar spine flattens $40^{\circ}-43^{\circ}$ during sitting ${ }^{51,167}$ and flexes an average of $40^{\circ}$ during lifting. ${ }^{122}$ Although body mass index does not correlate with the degree of lumbar lordosis, it is strongly correlated with lumbar spine ROM..$^{32,65,125,134,208}$ High body mass index limits lumbar ROM in pediatric patients ${ }^{208}$ and in workers lifting objects ${ }^{65}$ and is particularly limiting in seated postures. ${ }^{134}$

There are significant mechanical implications of degenerative lordosis. Mechanically, postural degeneration becomes a positive feedback cycle of worsening conditions. In a healthy spine the center of rotation at each spinal level is within the vertebral body during passive 


\section{J. Sparrey et al.}

standing (Halverson P, Bowden A, Stratton E, et al., presentation at the 55th Orthopaedic Research Society Annual Meeting, February 22-25, 2009, Las Vegas, NV), meaning muscles are only acting to stabilize the spine but not support the mass of the head, arms, and trunk. Relaxed standing posture, when balanced, is only $7 \%$ more energetically expensive than supine relaxing. ${ }^{127}$ However, slight changes in sagittal balance resulting from postural changes lead to increased muscle activity in the erector spinae to oppose the forward rotation of the body. ${ }^{57}$ The increased muscle activity increases the compression in the spine, leading to creep in the intervertebral discs. The loss of disc height from constant loading brings the facet joints closer together. With time, the facet joints become close enough to touch and begin carrying a portion of the spinal load.52 Altering the load sharing in the lumbar spine due to disc degeneration shields the anterior vertebral body from loading in upright postures and reduces the bone volume fraction in the vertebral body. ${ }^{6}$ However, in flexed postures loading in the anterior vertebral body is independent of disc morphology. This can lead to overloading in the weakened anterior vertebral body in flexion and spine fractures.

Mechanics in the lumbar spine are of particular interest because lumbar vertebrae and intervertebral discs experience the greatest mechanical loads in the spine. They are also the most common site of degenerative changes and low-back pain. ${ }^{19}$ Mechanical loading of the lumbar spine has been studied extensively in isolated in vitro preparations. These studies have shown that the distribution of loading across the vertebrae is a function of posture $^{108}$ and spine health..$^{6,150}$ In a healthy spine the neural arch carries negligible compressive load. ${ }^{52}$ However, in a degenerative spine subjected to prolonged compressive creep loading in a standing posture, the neural arch may resist up to $70 \%$ of the compressive force. ${ }^{5}$ The effects of posture on load distribution in the spine become exaggerated when disc height is reduced by pathological changes or sustained loading. ${ }^{52}$

\section{Musculature and Lumbar Lordosis}

The degree of lumbar lordosis may be constrained by vertebral body wedging and disc morphology; however, spinal muscle strength also dictates the degree of lordotic curve. ${ }^{178}$ At the extreme, activities that result in extensor muscle atrophy such as farm work in hyperflexed postures for long periods (9-10 hrs/day) or extended bed rest result in a significant loss of lumbar lordosis. ${ }^{29,186}$ Conversely, overuse and overdevelopment of musculature has also been shown to correlate with disc degeneration..$^{14}$ In patients with chronic low-back pain, targeted back exercises proved less effective than walking for reducing pain. ${ }^{87}$ Walking introduces dynamic motion in the spine and instability that requires moderate spine extensor muscle activity $(4 \%-13 \%$ of their maximum). ${ }^{135}$ In contrast, simple isometric back exercises result in much greater extensor muscle activation (24\%-42\% of maximum). ${ }^{71}$ Sitting results in reduced muscle activation that correlates with lumbar spine flexion. ${ }^{136}$ Slouched, seated postures resulted in extensor muscles shutting off almost completely, a phenomenon called flexion relaxation. ${ }^{41,48,136}$ It is likely that preserved spinal posture is achieved through finding an optimum balance of strength and flexibility of the joints.

Spine biomechanics research indicates that the extensor muscles generate a follower load. This refers to the resultant force that is tangential to the sagittal spinal curvature and allows the lumbar spine to support the weight of the upper body. The extensor muscles are also critical for maintaining stability during movement. ${ }^{11,76,101,145}$ Recent modeling suggests that a spine with large lordosis requires a greater follower load in the standing position than one with minimal lordosis. ${ }^{130}$ Since muscle force is proportional to muscle volume, ${ }^{7,33,61,94}$ increased lumbar lordosis requires larger extensor musculature to provide sufficient follower loads and sagittal stability. Previous studies showed the degree of lumbar lordosis correlated with extensor muscle volume ${ }^{131}$ and extensor muscle strength, ${ }^{178}$ while decreased extensor muscle volume correlated with back pain. . $^{50,83,96,131,198}$ There is strong evidence that early intervention may be effective in correcting posture problems in young subjects by improving core muscle balance. ${ }^{167}$ However, the long-term outcomes of such an intervention are unknown. In addition, it is unclear if muscle strengthening could be equally effective in older patients or those showing early signs of postural degeneration.

Whether the relationship between lumbar lordosis and extensor muscle size is causative or correlative is not yet clear. Several studies have shown that spine shape correlates with vertebrae morphology and orientation of the posterior elements. ${ }^{27,132}$ Variations in these parameters affect the forces required to stabilize the spine, which may manifest as changes in extensor muscle volume. Conversely, variations in muscle size may be the driving force in lumbar curvature. Several studies have shown a reduction in lumbar lordosis believed to be associated with agerelated loss of muscle mass; ${ }^{75,185}$ however, this may also be explained by other age-related changes such as decreased disc height, anterior wedging, or increased spinous process height. ${ }^{12,185}$ The relationship between lumbar lordosis and spinal musculature is complex and warrants further anatomical and clinical analysis.

\section{Perturbing the Balanced Spine}

Maintaining upright posture requires that the center of pressure due to the mass of the standing person be contained within his or her base of support (Fig. 2). Human subjects have shown a variety of adaptive strategies to ensure balanced standing in the face of changing postures. Experiments on healthy subjects walking and standing in a variety of postures suggest that increased muscle activity and energy expenditure result from stooped posture. In one study, healthy subjects were asked to maintain upright, $25^{\circ}$ and $50^{\circ}$ flexed postures during standing while their energy consumption was monitored. ${ }^{164}$ To maintain balance and keep their center of pressure in the same fore-aft position under their base of support, the subjects employed a number of compensatory strategies including increased hip flexion and ankle plantarflexion and increased cervical spine lordosis, which resulted in increased oxygen consumption $\left(25^{\circ}\right.$ and $50^{\circ}$ flexion increased consumption by $28 \%$ and $60 \%$, respectively, over 


\section{Etiology of lumbar lordosis and its pathophysiology: a review}

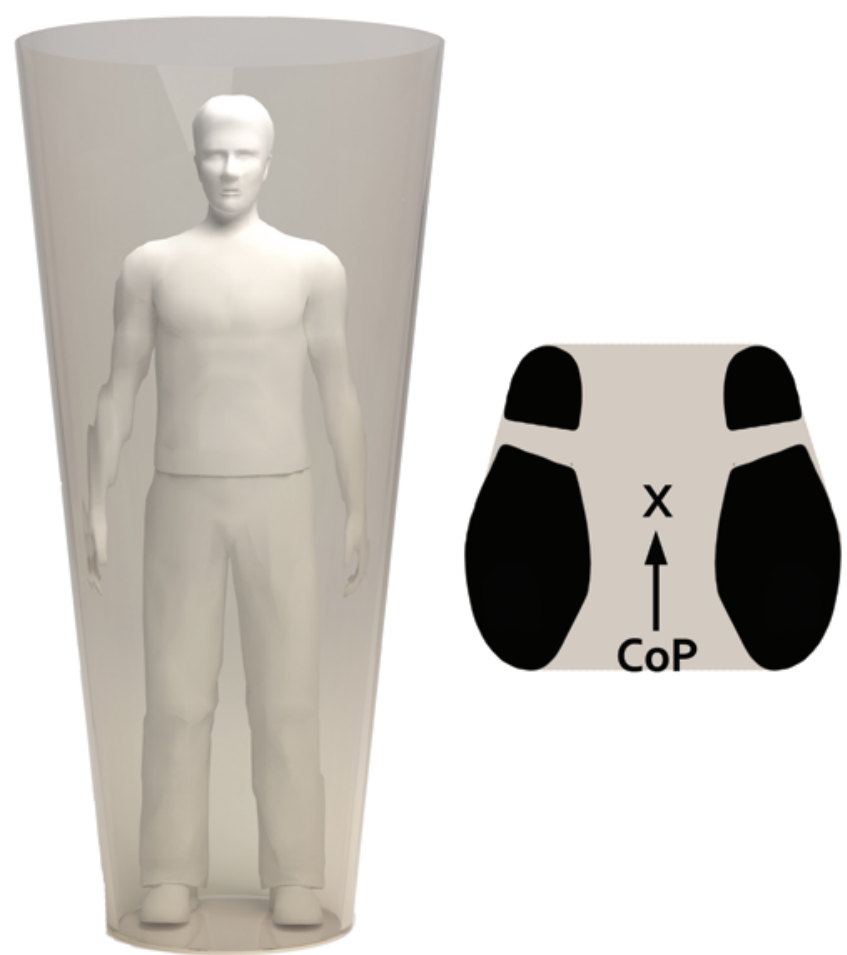

Fig. 2. Cone of economy and center of pressure (CoP). The cone of economy concept is based upon a cone centered at the foot of a standing patient projecting upward and outward. Alignment within the center of this cone is ergonomically favorable while excessive deviation in the anteroposterior or lateral planes requires increased energy expenditure to maintain balance and may produce fatigue, pain, or disability (Dubousset $\left.{ }^{54}\right)$. The center of pressure demonstrates the same mechanics in a different manner. If the center of pressure $(X)$ is centered within the base of support (shaded area), the person is most stable; as the center of pressure moves toward the edges of the base of support, a person is less stable and it is energetically more costly to maintain upright posture.

upright standing). Standing subjects who were directed to change their pelvic tilt angle showed an unconscious equivalent but opposite change in spinal curvature to compensate for the change in balance. ${ }^{112}$ Subjects asked to walk with flexed postures employed a bent knee, bent hip strategy similar to primates. ${ }^{163}$ This bent knee, bent hip strategy resulted in a $10 \%$ shorter stride length and an increase in steps per minute to maintain the same walking pace as the upright posture. These findings are seconded by experiments in chimpanzees trained to walk bipedally. ${ }^{183}$ For the majority of chimpanzees, bipedal ambulation with stooped posture results in bent knee, bent hip gait; however, in a subset of chimpanzees a different biomechanical approach was used that resulted in bipedal motion being more energy efficient than quadrupedal walking (though the bipedal chimps were still significantly less efficient than bipedal humans). Understanding that even slight changes in posture or the biomechanical approach to walking with compromised posture may affect bipedal efficiency is an important indicator of the need for early intervention in postural degeneration. Prolonged bent knee, bent hip gait, or excessive energy expenditure is likely to exacerbate postural degeneration in addition to triggering degeneration in other joints.
Postural correction and balance within the spine appears to be an unconscious response moderated by neurocontrols. In patients with postural deformities, the strategies to compensate for a loss of sagittal balance are consistent across individuals. Those with moderate lumbar flattening compensate by further extending their thoracic spine and hyperextending their hips. ${ }^{77}$ Patients with lumbar degenerative kyphosis who employed these compensatory strategies preoperatively showed an immediate resumption of normal thoracic kyphosis (increased $16^{\circ}$ postoperative) and sacral slope (increased $14^{\circ}$ postoperative) despite only their lumbar curvature being surgically restored. ${ }^{93}$ Deficits in proprioception and neurocontrol have been correlated with scoliotic deformities in growing children. ${ }^{119}$ However, little is known about the relationship between neurocontrol and postural degeneration in older patients.

Healthy individuals also employ unconscious postural correction strategies to maintain balance. During running, the pelvic tilt increases $15^{\circ}$ to $20^{\circ}$ to facilitate an increased stride length. ${ }^{112}$ The torso angle changes opposite to the pelvic angle to maintain the center of pressure within the base of support. In both walking and running the lumbar spine oscillates with each step. The magnitude of oscillation is $4^{\circ}-9^{\circ}$ for walking ${ }^{111}$ and $5^{\circ}-21^{\circ}$ for running. ${ }^{111,168}$ Maximum flexion of the lumbar spine correlated with toe off in the gait cycle while maximum extension occurred near the timing of heel strike. ${ }^{169}$ Walking and running both result in cyclic impacts to the body with each step which in turn applies a cyclic (or dynamic) load to the spine.

\section{Mechanobiology}

Researchers now widely recognize links between mechanical loading and the biological responses of human tissue. Long before structural failures (for example, fracture or disc herniation), significant biological changes are occurring in tissues as a result of mechanical loading. Mechanobiology may be either positive or negative. Load-bearing structures in the body, such as bones, cartilage, and discs, depend on mechanical loading to trigger biological processes that keep them healthy; however, excessive or abnormal mechanical loads may lead to detrimental adaptations in the tissues of the lumbar spine.

Several studies have characterized the effect of spinal degeneration on load distribution in the tissues (for review see Niosi and Oxland ${ }^{138}$ ). It is hypothesized that osteoporotic fractures in the spine may be a long-term result of changing load distributions in the spine. Slight variations in spinal curvature $\left(2^{\circ}\right)$ drastically reduce the loads seen by the vertebral body and disc and result in greater loads carried in the vertebral arches. ${ }^{5}$ Reduced loading in bone is known to lead to bone resorption. ${ }^{63}$ In the spine this may lead to resorption of bone in the vertebral bodies. In flexed postures, the vertebral arches are not loaded and the majority of compressive loading is carried by the weakened vertebral bodies, which may lead to osteoporotic fractures in the vertebrae. . $^{6,150}$

Seated posture requires flexion in the lumbar spine and concentrates the compressive load in the vertebral 


\section{J. Sparrey et al.}

bodies and intervertebral discs. However, there is little evidence in the spine biomechanics literature that this concentration of load in the disc during sitting is sufficient to cause injury. ${ }^{47}$ Static disc pressures, such as those occurring in prolonged standing or sitting, are, however, likely to disrupt the flow of nutrients into the disc, ${ }^{176,199}$ which may have implications for long-term disc health.

The intervertebral disc is an avascular structure; therefore, the flow of nutrients into the disc and removal of waste products from the disc requires convective transport and diffusion. While diffusion is the dominant factor in nutrient delivery, ${ }^{191}$ fluid flow out of the disc during normal daily activities appears to be a primary factor in waste removal. ${ }^{124}$ Normal daily activities result in a combined disc height loss of 13-21 $\mathrm{mm}^{144,156}$ and an average fluid loss of $0.9-1.3 \mathrm{~cm}^{3}$ per disc per day ${ }^{124,156}$ in healthy spines. Walking with a heavy load (40\% of body weight) produced an equivalent height and fluid loss in only 4 hours. ${ }^{88}$ Comparing the effects of different activities on fluid loss in the disc showed sitting resulted in $40 \%$ less disc height loss than walking. ${ }^{193}$ Although excessive disc height loss may be detrimental to disc health, height loss is necessary to generate pressure gradients that expel fluid (and remove waste) then allow for fluid influx during a diurnal cycle.

In addition to the magnitude of loading, the biological response of the intervertebral discs to mechanical loading is highly rate dependent. Mechanical studies demonstrate that dynamic loading on the disc at the frequency and loading magnitudes typical of bipedal walking or running increase nutrient flow. ${ }^{114}$ In contrast, static, high rate, or high magnitude loading are all detrimental to disc nutrition. ${ }^{184,199}$ Dynamic mechanical loading on a hydrated material such as the disc results in increased material stiffness when compared with static loading. ${ }^{98}$ Increased material stiffness leads to less deformation in the disc for a given load, protecting the disc from excessive height loss during dynamic activities such as walking.

\section{Biology}

The most common causes of degenerative lumbar deformity are osteoporosis and degenerative disc disease. ${ }^{49}$ Although historically viewed as a result of mechanical overuse, the Twin Spine Study demonstrated a significant role for genetic factors and a high heritability of lumbar disc degeneration, while environmental risk factors such as smoking and increased physical loading had surprisingly modest effects. ${ }^{17,18,165}$ Genetics explained $61 \%$ of the variation in disc degeneration in the upper lumbar spine (T12-L4) and only 32\% in the lower lumbar spine (L4S1). Aging and mechanical exposure combined explained $16 \%$ of the variation in the upper lumbar spine and $11 \%$ of the variation in the lower lumbar spine. In the lower lumbar spine, $57 \%$ of the variation in disc degeneration is not explained by genetics, mechanics, or age. ${ }^{19}$ A limitation of the Twin Spine Study is that it studied adult twins; therefore, variation attributed to genetics represents the upper limit of genetic influence and incorporates genetics and environmental exposures through childhood. ${ }^{19}$ Genetic studies led to the identification of two polymorphisms in the VDR gene associated with disc degeneration. ${ }^{195}$ Recent work also identified associations with genes encoding collagen, interleukins, and matrix metalloproteinases. ${ }^{19}$ Interestingly, the same research group who determined genetics to be the dominant factor in disc health found positive effects of moderate routine loading on disc health. ${ }^{196}$ This research coupled with earlier evolution research that observed marked difference in disc disease in tribesman compared with European males suggests that differences observed in these early populations may have been an effect of controlled genetic pools and not lifestyle.

Osteoporosis has a complex etiology that is determined by genetics and is modulated by hormonal, environmental, and nutritional factors. ${ }^{64}$ Vertebral wedge fractures are a common result of osteoporosis and contribute to overall postural degeneration. Up to $90 \%$ of spine and hip fractures in elderly women and $70 \%$ in elderly men may be attributed to osteoporosis. ${ }^{133}$ Osteoporosis is defined as bone mineral density values that are more than 2.5 standard deviations below the young adult average. ${ }^{209}$ Bone mineral density is the major determinant of bone strength and osteoporotic fracture risk. ${ }^{209}$ Genetics account for $50 \%-80 \%$ of the variation in individual bone mass. ${ }^{149,179}$ Genetic studies have identified vitamin D receptor (VDR), ${ }^{188}$ collagen Type I aI (COCIAI),${ }^{70}$ estrogen receptors (ESRI), ${ }^{82}$ transforming growth factor $\beta 1$ (TGFB1), ${ }^{105}$ lipoprotein receptor-related protein 5 (LRP5), ${ }^{69}$ sclerostin (SOST), ${ }^{190}$ TCIRG1, ${ }^{182}$ and CLCN713 to be associated with osteoporosis. There are multiple polymorphisms within each gene that show varying degrees of disease linkage with osteoporosis. ${ }^{64,153}$ Studies in the field of genetics and osteoporosis have mostly been underpowered, leading to conflicting results and findings that cannot be replicated. Large-scale, longitudinal studies combined with computation bioinformatics will assist in identifying and validating the effects of gene polymorphisms in bone mineral density regulation and osteoporosis risk. Integrating genetics into population screening for osteoporosis will only be warranted once specific genetic links have been clearly established.

Genetics are also linked with an individual's degree of lumbar lordosis and ROM. A recent study of monozygotic twins, dizygotic twins, same-sex siblings, and different-sex siblings showed a strong correlation between the degree of lumbar lordosis and genetic similarity. ${ }^{53}$ Monozygotic twins showed a high correlation in the degree of lordosis $(R=0.65)$, while opposite-sex siblings showed low correlation $(\mathrm{R}=0.14)$. In another study, $\mathrm{ROM}$ for normal lumbar spines was also shown to vary by race, with Turkish men showing greater than $25 \%$ decrease in lumbar flexion ${ }^{45}$ compared with British men. ${ }^{1}$

\section{Clinical Discussion}

Given the importance of lumbar lordosis in the evolution of the human spine and its role in our transition to bipedalism, it is not surprising that loss of sagittal balance contributes to significant pain and disability. ${ }^{67,104,170}$ Sagittal malalignment also results in increased energy expenditure and induces a variety of compensatory measures including knee flexion, pelvic retroversion, and thoracic hypokyphosis. ${ }^{104,171,172}$ Studies have shown that 


\section{Etiology of lumbar lordosis and its pathophysiology: a review}

surgical correction of sagittal malalignment leads to improvements in a variety of health-related quality of life measurements. ${ }^{67,172}$ In patients with lumbar degenerative kyphosis, surgical restoration of lumbar lordosis results in spontaneous resolution of pelvic retroversion and thoracic hypokyphosis..$^{92,93}$

The role of musculature in supporting lumbar lordosis is clearly established through observations of humanspecific evolutionary changes in spinal musculature, the mechanical role of spinal muscles, and the correlations between muscle volume and postural changes. However, clinical research has not yet established a cause or effect relationship between spinal muscles and postural changes. Establishing a timeline for degenerative postural changes and musculature may provide insights into the effectiveness and timing of muscle development rehabilitation strategies. Effective conservative treatments also depend on identifying patients at risk for postural degeneration before they become symptomatic. Recent research to establish definitions of normal lumbar curvature and optimize lordosis measurement methods ${ }^{25}$ provides an important foundation to establish early diagnosis and track postural degeneration. The relationship between vertebral structure and posture defined for studying human evolution may provide a means for early identification of small deviations from an individual's optimal posture. These structure-postural relations may also be able to predict the degree of spontaneous correction possible in the thoracic spine following the restoration of lumbar lordosis.

Lumbar flattening often results from degenerative changes in the spine. Osteoporotic wedge fractures in the vertebrae ${ }^{81}$ and degenerative disc disease ${ }^{16}$ both correlated with reduced lordosis in the lumbar spine. Muscle weakness also correlated with a loss of lordosis. Older patients show a reduction in lumbar lordosis as a result of these degenerative changes..$^{75,143}$ However, the degree of lumbar lordosis in normal individuals is highly variable $\left(41^{\circ}-70^{\circ}\right)^{23,194}$ and broadly overlaps with measures of degenerative hypolordosis $\left(-40^{\circ}\right.$ to $\left.67^{\circ}\right) .^{31,99}$ Therefore, defining threshold values for degenerative lumbar curvature in isolation is meaningless. Recently, Schwab et al. ${ }^{173}$ defined postural deformity criteria for the spine. Lumbar spine deformity is determined by the difference between a patient's lumbar lordosis (measured by Cobb angle) and PI $\left(\mathrm{LL}=\mathrm{PI} \pm 9^{\circ}\right)$. These deformity criteria closely correlate with health-related quality of life measures. ${ }^{187}$

Radiographic metrics play an important role in diagnosing sagittal alignment and guiding surgical planning. ${ }^{8}$ The standard modality for assessing sagittal alignment is the lateral 36-in standing radiograph. Although a patient's deformity may be concentrated in the lumbar spine, diagnosing postural deformity includes consideration of the entire spinopelvic structure. The sagittal vertical axis (SVA) is the most common global measure of sagittal alignment and is defined as the horizontal offset between the C-7 plumb line and posterior superior aspect of the S-1 vertebral body. The pelvis is a significant contributor to sagittal alignment and the PI, pelvic tilt, and sacral slope are also measured (Fig. 1). ${ }^{109,141}$ Lumbar lordosis in healthy individuals is highly correlated with both pelvic incidence (0.68) and sacral slope (-0.76). ${ }^{194}$ However, PI is a fixed measure, independent of standing position, whereas sacral slope may be affected by pelvic retroversion and knee flexion typical of patients with significant loss of lumbar lordosis. ${ }^{104,171} \mathrm{~A}$ patient's PI assists in determining the degree of total lumbar lordosis required to achieve better sagittal alignment; however, total spine correction can be obtained from an infinite combination of local curves (Fig. 3). Research on normal spines demonstrates a consistent pattern of curvature distribution in the lumbar spine, with the L5-S1 level contributing $40 \%$ of the total lumbar lordosis. ${ }^{22}$ However, there is significant variation in the pattern. Further research is required to determine the effect of curvature distribution in the lumbar spine on patient outcome and to develop methods to define the optimal distribution of lordosis in the fixed lumbar spine.

The goal of treating lumbar deformity is to improve a patient's quality of life. Lumbar deformity may be treated conservatively or surgically. Patients with mild to moderate symptoms may be treated with bracing, pain control, and physical therapy; however, none of these are curative and at best prevent the progression of a deformity. Conservative management is more effective in patients with flexible deformities than in those with fixed deformities. ${ }^{161}$ Patients managed nonoperatively have shown increased use of narcotics, epidural blocks, analgesics, pain management referrals, and bed rest. ${ }^{66}$ In cases of degenerative disease, a small number of patients benefit from spinal steroid injections to improve pain and function; however, more than two-thirds require invasive treatment within 2 years.$^{40}$ Although the cost of spinal surgery exceeds that of nonsurgical management, treatment effects significantly favor surgery. ${ }^{62}$ There are disadvantages to surgery, particularly the loss of flexibility involved in pelvic fusion and peri- and postoperative complications. In addition, not all patients are viable candidates because of medical comorbidities or personal preference. However, the advantages of surgical correction of sagittal malalignment and the improvements in health-related quality of life measures are widely recognized..$^{67,172}$

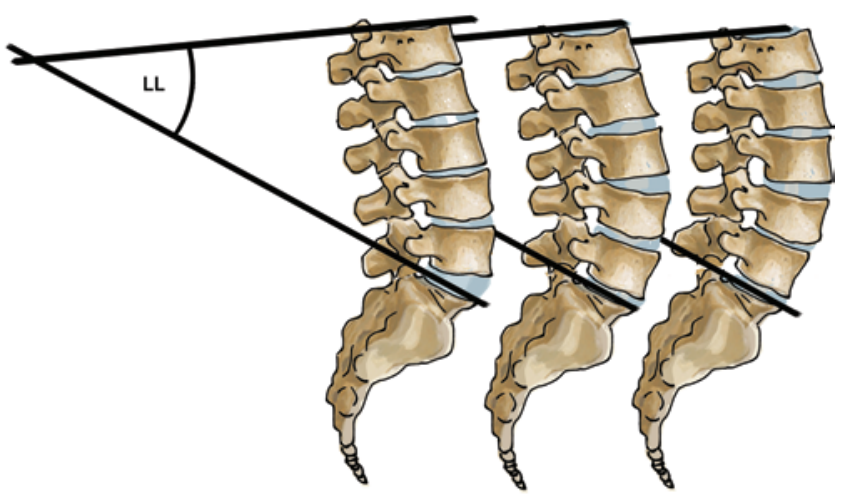

FIG. 3. Illustration showing the variation in lumbar lordosis (LL). The Cobb angle is a standard measure of lumbar lordosis and is the angle between the sacral plate and the superior surface of the L-1 vertebra. Although patients may present with the same measure of lumbar lordosis, the relative angle of each vertebra in the lumbar spine can vary, giving the surgeon multiple options for the curvature of spinal fusion. There is currently no protocol for optimizing the distribution of curvature correction in the lumbar spine to an individual patient. Copyright Andrew McNichol. Published with permission. 


\section{J. Sparrey et al.}

The goals of surgical treatment are restoration of proper spinal alignment and alleviation of symptoms. Surgery should strive to achieve an SVA less than $5 \mathrm{~cm}$ and pelvic tilt less than $20^{\circ}$, while alleviating PI/lumbar lordosis mismatch (that is, $\mathrm{PI}=$ lumbar lordosis $\left.\pm 9^{\circ}\right) .^{173}$ Ideal alignment allows minimal muscle expenditure while standing, reflected in the "Cone of Economy" principle described by Jean Dubousset (Fig. 2). ${ }^{54}$ However, surgically fixed lumbar lordosis may result in increased muscle activity in seated postures, where a normal lumbar spine would flatten and reduce extensor muscle activity. Mechanical studies of spine posture demonstrate flexion relaxation in the extensor muscles during relaxed seated postures. Surgical fixation with constant lumbar lordosis may inhibit the flexion relaxation phenomenon. Further study is needed to determine the energetic costs of surgically fixed lumbar lordosis in nonstanding activities.

Since global sagittal malalignment correlates with health-related quality of life scores for patients with spinal deformity, achieving appropriate postoperative alignment is critical. Improved recognition of this relationship has led to increased use of multilevel fusions and posterior osteotomies. Spinal osteotomies allow for correction of rigid deformity patterns and can be applied to a variety of pathologies including adult scoliosis, flatback syndrome, iatrogenic fixed sagittal imbalance, kyphotic decompensation syndrome, and flat buttock. ${ }^{174}$ Multilevel fusions can lead to adjacent level degeneration ${ }^{56,72}$ and coronal imbalance ${ }^{148}$ when not performed optimally. Adjacent level effects are significantly reduced in patients with a normal postoperative C-7 plumbline ${ }^{102}$ and in lumbar spine fusions that extended above T-10.100

Outcomes in spinal deformity surgery vary by the procedure type, level involvement, and patient demographic. Although there is debate over the optimal management of symptomatic spinal deformity, surgical treatment is associated with improved outcomes compared with conservative nonoperative management. ${ }^{37,180,181}$ Since sagittal plane malalignment is the main radiographic driver of disability in these patients, ${ }^{67,104}$ correction of spinopelvic parameters is critical. Restoration of sagittal alignment is associated with improved postoperative outcomes and fewer long-term complications. ${ }^{89,100}$ However, surgical corrections of postural deformities have high complication rates. ${ }^{3,152}$ Complications are significantly increased by advanced age, ${ }^{43,58,129}$ medical comorbidities, ${ }^{15,192}$ nutritional status, ${ }^{106}$ length of fusion, ${ }^{43}$ and extension of fusion to the sacrum. ${ }^{36}$ The history of previous surgery has been shown to increase complication rates in some studies ${ }^{68}$ but not others. ${ }^{115}$ Women also experience more complications following spinal fusion than men, even after accounting for osteoporosis. ${ }^{58}$ This may be due to sexual dimorphism in the structure of the spine and vertebrae as observed through studies of human evolution. Further research is required to determine any differences in diagnosis and treatment of postural deformity based on dimorphic structures in the spine. Among adults undergoing surgical correction of sagittal plane deformity, the best health-related quality of life outcomes are achieved in patients who undergo substantial correction of SVA, defined as greater than $120 \mathrm{~mm}$ and at least $66 \% .^{34}$ Although lower amounts of correction can still yield clini- cal improvements, the minimal clinically important difference in health-related quality of life scores was not significantly different for such mild or moderate degrees of correction, stressing the need for complete sagittal plane correction to achieve the best clinical outcomes. Surgical correction of a severe spinal deformity is complex, risky, and expensive. Identifying patients who are at risk for postural deformity and developing methods for monitoring and treating patients early will reduce the need for these invasive surgeries and improve patient quality of life.

Mechanics, biology, and evolution all point to the need for a stable and flexible spine to perform normal daily activities. Dynamic spine constructs propose to accomplish stabilization while maintaining flexibility after surgery; however, current systems have been plagued by complications and failures. ${ }^{90,121}$ Current dynamic systems are not suitable for multilevel postural corrections. ${ }^{9}$ An effective dynamic system should help to preserve muscle strength and bone health by allowing the dynamic motion for which the human body evolved. A dynamic fixation system suitable for postural deformities could significantly improve patient quality of life by reducing the energetic costs of fixed lordosis and reduce complications by eliminating load and deformation concentrations in the spinal levels above and below the fusion instrumentation. An effective method for restoring spine posture while maintaining flexibility remains an elusive goal. Future research should aim to develop new dynamic fixation tailored to spinal deformity treatment. In addition, more research is needed on the effect of rigid fixation on patient activities, energetic costs, and postural compensation strategies for large ROM activities such as sitting or bending.

\section{Conclusions}

The evolution and development of human lumbar lordosis highlight the interdependence of pelvic structure and lumbar lordosis. Lumbar lordosis is dictated by pelvic incidence, spinal musculature, vertebral wedging, and disc health. A change in any of these factors affects the distribution of mechanical loading in the spine. Disc degeneration and osteoporosis are strongly influenced by genetics, with limited effects of loading or environment. Therefore, postural degeneration is not simply a result of misusing our evolved spines. Spinal musculature shows a strong correlation with lumbar lordosis and may provide an opportunity for early intervention or prevention of postural deformities. Developing tools for early identification of patients at risk for postural deformities through patient history (genetics, mechanics, and environmental exposure) and tracking postural changes over time should reduce the need for complex and costly spinal fixation.

\section{Acknowledgment}

Illustrations for the manuscript were created by Andrew McNichol.

\section{Disclosure}

Dr. Sparrey was funded by a Canadian Institutes for Health Research Postdoctoral Fellowship. Dr. Smith reports that he is a consultant for Biomet, DePuy, and Medtronic and that he receives non- 
study-related clinical or research support from DePuy. Dr. Ames reports that he is a consultant for DePuy, Stryker, and Medtronic; he owns stock in Visualase, Doctors Research Group, and Baxano Surgical; he is a patent holder with Fish \& Richardson, P.C.; and receives royalties from Biomet Spine and Aesculap.

Author contributions to the study and manuscript preparation include the following. Conception and design: Sparrey, Bailey, Ames. Analysis and interpretation of data: Sparrey. Drafting the article: Sparrey, Bailey, Safaee. Critically revising the article: all authors. Reviewed submitted version of manuscript: all authors. Approved the final version of the manuscript on behalf of all authors: Sparrey.

\section{References}

1. Abitbol MM: Evolution of the lumbosacral angle. Am J Phys Anthropol 72:361-372, 1987

2. Abitbol MM: Evolution of the sacrum in hominoids. Am J Phys Anthropol 74:65-81, 1987

3. Acosta FL Jr, McClendon J Jr, O'Shaughnessy BA, Koller H, Neal CJ, Meier O, et al: Morbidity and mortality after spinal deformity surgery in patients 75 years and older: complications and predictive factors. Clinical article. J Neurosurg Spine 15:667-674, 2011

4. Adams MA, Hutton WC: The effect of posture on the lumbar spine. J Bone Joint Surg Br 67:625-629, 1985

5. Adams MA, Hutton WC: The effect of posture on the role of the apophysial joints in resisting intervertebral compressive forces. J Bone Joint Surg Br 62:358-362, 1980

6. Adams MA, Pollintine P, Tobias JH, Wakley GK, Dolan P: Intervertebral disc degeneration can predispose to anterior vertebral fractures in the thoracolumbar spine. J Bone Miner Res 21:1409-1416, 2006

7. Akagi R, Takai Y, Ohta M, Kanehisa H, Kawakami Y, Fukunaga T: Muscle volume compared to cross-sectional area is more appropriate for evaluating muscle strength in young and elderly individuals. Age Ageing 38:564-569, 2009

8. Ames CP, Smith JS, Scheer JK, Bess S, Bederman SS, Deviren $\mathrm{V}$, et al: Impact of spinopelvic alignment on decision making in deformity surgery in adults. A review. J Neurosurg Spine 16:547-564, 2012

9. Anand N, Baron EM: Role of dynesys as pedicle-based nonfusion stabilization for degenerative disc disorders. Adv Orthop 2012:218385, 2012

10. Asfaw B, White T, Lovejoy O, Latimer B, Simpson S, Suwa G: Australopithecus garhi: a new species of early hominid from Ethiopia. Science 284:629-635, 1999

11. Aspden RM: The spine as an arch. A new mathematical model. Spine (Phila Pa 1976) 14:266-274, 1989

12. Aylott CE, Puna R, Robertson PA, Walker C: Spinous process morphology: the effect of ageing through adulthood on spinous process size and relationship to sagittal alignment. Eur Spine J 21:1007-1012, 2012

13. Balemans W, Van Wesenbeeck L, Van Hul W: A clinical and molecular overview of the human osteopetroses. Calcif Tissue Int 77:263-274, 2005

14. Baranto A, Hellström M, Cederlund CG, Nyman R, Swärd L: Back pain and MRI changes in the thoraco-lumbar spine of top athletes in four different sports: a 15-year follow-up study. Knee Surg Sports Traumatol Arthrosc 17:1125-1134, 2009

15. Baron EM, Albert TJ: Medical complications of surgical treatment of adult spinal deformity and how to avoid them. Spine (Phila Pa 1976) 31 (19 Suppl):S106-S118, 2006

16. Barrey C, Jund J, Noseda O, Roussouly P: Sagittal balance of the pelvis-spine complex and lumbar degenerative diseases. A comparative study about 85 cases. Eur Spine J 16:1459-1467, 2007

17. Battié MC, Videman T, Gibbons LE, Fisher LD, Manninen H, Gill K: 1995 Volvo Award in clinical sciences. Determinants of lumbar disc degeneration. A study relating lifetime expo- sures and magnetic resonance imaging findings in identical twins. Spine (Phila Pa 1976) 20:2601-2612, 1995

18. Battié MC, Videman T, Gill K, Moneta GB, Nyman R, Kaprio J, et al: 1991 Volvo Award in Clinical Sciences. Smoking and lumbar intervertebral disc degeneration: an MRI study of identical twins. Spine (Phila Pa 1976) 16:1015-1021, 1991

19. Battié MC, Videman T, Kaprio J, Gibbons LE, Gill K, Manninen $\mathrm{H}$, et al: The Twin Spine Study: contributions to a changing view of disc degeneration. Spine J 9:47-59, 2009

20. Bauer HR: Chimpanzee bipedal locomotion in the Gombe National Park, East Africa. Primates 18:913-921, 1977

21. Been E, Barash A, Marom A, Aizenberg I, Kramer PA: A new model for calculating the lumbar lordosis angle in early hominids and in the spine of the neanderthal from Kebara. Anat Rec (Hoboken) 293:1140-1145, 2010

22. Been E, Barash A, Marom A, Kramer PA: Vertebral bodies or discs: which contributes more to human-like lumbar lordosis? Clin Orthop Relat Res 468:1822-1829, 2010

23. Been E, Barash A, Pessah H, Peleg S: A new look at the geometry of the lumbar spine. Spine (Phila Pa 1976) 35:E1014E1017, 2010

24. Been E, Gómez-Olivencia A, Kramer PA: Lumbar lordosis of extinct hominins. Am J Phys Anthropol 147:64-77, 2012

25. Been E, Kalichman L: Lumbar lordosis. Spine J 14:87-97, 2014

26. Been E, Peleg S, Marom A, Barash A: Morphology and function of the lumbar spine of the Kebara 2 Neandertal. Am J Phys Anthropol 142:549-557, 2010

27. Been E, Pessah H, Been L, Tawil A, Peleg S: New method for predicting the lumbar lordosis angle in skeletal material. Anat Rec (Hoboken) 290:1568-1573, 2007

28. Been E, Pessah H, Peleg S, Kramer PA: Sacral orientation in hominin evolution. Adv Anthropol 3:133-141, 2013

29. Belavý DL, Armbrecht G, Richardson CA, Felsenberg D, Hides JA: Muscle atrophy and changes in spinal morphology: is the lumbar spine vulnerable after prolonged bed-rest? Spine (Phila Pa 1976) 36:137-145, 2011

30. Bergenudd H, Nilsson B, Udén A, Willner S: Bone mineral content, gender, body posture, and build in relation to back pain in middle age. Spine (Phila Pa 1976) 14:577-579, 1989

31. Berven SH, Deviren V, Smith JA, Hu SH, Bradford DS: Management of fixed sagittal plane deformity: outcome of combined anterior and posterior surgery. Spine (Phila Pa 1976) 28:1710-1716, 2003

32. Bible JE, Simpson AK, Emerson JW, Biswas D, Grauer JN: Quantifying the effects of degeneration and other patient factors on lumbar segmental range of motion using multivariate analysis. Spine (Phila Pa 1976) 33:1793-1799, 2008

33. Blazevich AJ, Cannavan D, Horne S, Coleman DR, Aagaard P: Changes in muscle force-length properties affect the early rise of force in vivo. Muscle Nerve 39:512-520, 2009

34. Blondel B, Schwab F, Ungar B, Smith J, Bridwell K, Glassman $\mathrm{S}$, et al: Impact of magnitude and percentage of global sagittal plane correction on health-related quality of life at 2-years follow-up. Neurosurgery 71:341-348, 2012

35. Bourke JB: Trauma and degenerative diseases in ancient Egypt and Nubia. J Hum Evol 1:225-232, 1972

36. Bridwell KH, Edwards CC II, Lenke LG: The pros and cons to saving the L5-S1 motion segment in a long scoliosis fusion construct. Spine (Phila Pa 1976) 28:S234-S242, 2003

37. Bridwell KH, Glassman S, Horton W, Shaffrey C, Schwab F, Zebala LP, et al: Does treatment (nonoperative and operative) improve the two-year quality of life in patients with adult symptomatic lumbar scoliosis: a prospective multicenter evidence-based medicine study. Spine (Phila Pa 1976) 34:21712178,2009

38. Brown F, Harris J, Leakey R, Walker A: Early Homo erectus skeleton from west Lake Turkana, Kenya. Nature 316:788792, 1985

39. Brunet M, Guy F, Pilbeam D, Mackaye HT, Likius A, Ahounta 


\section{J. Sparrey et al.}

D, et al: A new hominid from the upper miocene of Chad, central Africa. Nature 418: 145-151, 2002

40. Buttermann GR: The effect of spinal steroid injections for degenerative disc disease. Spine J 4:495-505, 2004

41. Callaghan JP, Dunk NM: Examination of the flexion relaxation phenomenon in erector spinae muscles during short duration slumped sitting. Clin Biomech (Bristol, Avon) 17:353360,2002

42. Caspari R, Lee SH: Older age becomes common late in human evolution. Proc Natl Acad Sci U S A 101:10895-10900, 2004

43. Cheh G, Bridwell KH, Lenke LG, Buchowski JM, Daubs MD, Kim Y, et al: Adjacent segment disease following lumbar/ thoracolumbar fusion with pedicle screw instrumentation: a minimum 5-year follow-up. Spine (Phila Pa 1976) 32:22532257, 2007

44. Choufani E, Jouve JL, Pomero V, Adalian P, Chaumoitre K, Panuel M: Lumbosacral lordosis in fetal spine: genetic or mechanic parameter. Eur Spine J 18:1342-1348, 2009

45. Cidem M, Karacan I, Uludag M: Normal range of spinal mobility for healthy young adult Turkish men. Rheumatol Int 32:2265-2269, 2012

46. Cil A, Yazici M, Uzumcugil A, Kandemir U, Alanay A, Alanay Y, et al: The evolution of sagittal segmental alignment of the spine during childhood. Spine (Phila Pa 1976) 30:93-100, 2005

47. Claus A, Hides J, Moseley GL, Hodges P: Sitting versus standing: does the intradiscal pressure cause disc degeneration or low back pain? J Electromyogr Kinesiol 18:550-558, 2008

48. Claus AP, Hides JA, Moseley GL, Hodges PW: Different ways to balance the spine: subtle changes in sagittal spinal curves affect regional muscle activity. Spine (Phila Pa 1976) 34:E208-E214, 2009

49. Daffner SD, Vaccaro AR: Adult degenerative lumbar scoliosis. Am J Orthop 32:77-82, 2003

50. Danneels LA, Vanderstraeten GG, Cambier DC, Witvrouw EE, De Cuyper HJ: CT imaging of trunk muscles in chronic low back pain patients and healthy control subjects. Eur Spine J 9:266-272, 2000

51. De Carvalho DE, Soave D, Ross K, Callaghan JP: Lumbar spine and pelvic posture between standing and sitting: a radiologic investigation including reliability and repeatability of the lumbar lordosis measure. J Manipulative Physiol Ther 33:48-55, 2010

52. Dolan P, Adams MA: Recent advances in lumbar spinal mechanics and their significance for modelling. Clin Biomech (Bristol, Avon) 16 (Suppl 1):S8-S16, 2001

53. Dryden IL, Oxborrow N, Dickson R: Familial relationships of normal spine shape. Stat Med 27:1993-2003, 2008

54. Dubousset J: Three-dimensional analysis of the scoliotic deformity, in Weinstein SL (ed): The Pediatric Spine: Principles and Practice. New York: Raven Press, 1994, pp 479-496

55. Eaton SB, Strassman BI, Nesse RM, Neel JV, Ewald PW, Williams GC, et al: Evolutionary health promotion. Prev Med 34:109-118, 2002

56. Edwards CC II, Bridwell KH, Patel A, Rinella AS, Jung Kim $\mathrm{Y}$, Berra $\mathrm{AB}$, et al: Thoracolumbar deformity arthrodesis to L5 in adults: the fate of the L5-S1 disc. Spine (Phila Pa 1976) 28:2122-2131, 2003

57. Enomoto M, Ukegawa D, Sakaki K, Tomizawa S, Arai Y, Kawabata $S$, et al: Increase in paravertebral muscle activity in lumbar kyphosis patients by surface electromyography compared with lumbar spinal canal stenosis patients and healthy volunteers. J Spinal Disord Tech 25:E167-E173, 2012

58. Faciszewski T, Winter RB, Lonstein JE, Denis F, Johnson L: The surgical and medical perioperative complications of anterior spinal fusion surgery in the thoracic and lumbar spine in adults. A review of 1223 procedures. Spine (Phila Pa 1976) 20:1592-1599, 1995
59. Fahrni WH, Trueman GE: Comparative radiological study of the spines of a primitive population with North Americans and northern Europeans. J Bone Joint Surg Br 47:552-555, 1965

60. Filler AG: Emergence and optimization of upright posture among hominiform hominoids and the evolutionary pathophysiology of back pain. Neurosurg Focus 23(1):E4, 2007

61. Folland JP, Williams AG: The adaptations to strength training: morphological and neurological contributions to increased strength. Sports Med 37:145-168, 2007

62. Fritzell P, Hägg O, Jonsson D, Nordwall A, Swedish Lumbar Spine Study Group: Cost-effectiveness of lumbar fusion and nonsurgical treatment for chronic low back pain in the Swedish Lumbar Spine Study: a multicenter, randomized, controlled trial from the Swedish Lumbar Spine Study Group. Spine (Phila Pa 1976) 29:421-434, 2004

63. Frost HM: Wolff's Law and bone's structural adaptations to mechanical usage: an overview for clinicians. Angle Orthod 64:175-188, 1994

64. Gennari L, Merlotti D, De Paola V, Calabrò A, Becherini L, Martini G, et al: Estrogen receptor gene polymorphisms and the genetics of osteoporosis: a HuGE review. Am J Epidemiol 161:307-320, 2005

65. Gilleard W, Smith T: Effect of obesity on posture and hip joint moments during a standing task, and trunk forward flexion motion. Int J Obes (Lond) 31:267-271, 2007

66. Glassman SD, Berven S, Kostuik J, Dimar JR, Horton WC, Bridwell K: Nonsurgical resource utilization in adult spinal deformity. Spine (Phila Pa 1976) 31:941-947, 2006

67. Glassman SD, Bridwell K, Dimar JR, Horton W, Berven S, Schwab F: The impact of positive sagittal balance in adult spinal deformity. Spine (Phila Pa 1976) 30:2024-2029, 2005

68. Glassman SD, Carreon LY, Dimar JR, Campbell MJ, Puno RM, Johnson JR: Clinical outcomes in older patients after posterolateral lumbar fusion. Spine J 7:547-551, 2007

69. Gong Y, Slee RB, Fukai N, Rawadi G, Roman-Roman S, Reginato AM, et al: LDL receptor-related protein 5 (LRP5) affects bone accrual and eye development. Cell 107:513-523, 2001

70. Grant SF, Reid DM, Blake G, Herd R, Fogelman I, Ralston SH: Reduced bone density and osteoporosis associated with a polymorphic Spl binding site in the collagen type I alpha 1 gene. Nat Genet 14:203-205, 1996

71. Guo LY, Wang YL, Huang YH, Yang CH, Hou YY, Harn HI, et al: Comparison of the electromyographic activation level and unilateral selectivity of erector spinae during different selected movements. Int J Rehabil Res 35:345-351, 2012

72. Ha Y, Maruo K, Racine L, Schairer WW, Hu SS, Deviren V, et al: Proximal junctional kyphosis and clinical outcomes in adult spinal deformity surgery with fusion from the thoracic spine to the sacrum: a comparison of proximal and distal upper instrumented vertebrae. Clinical article. J Neurosurg Spine 19:360-369, 2013

73. Haeusler M, Martelli SA, Boeni T: Vertebrae numbers of the early hominid lumbar spine. J Hum Evol 43:621-643, 2002

74. Haeusler M, Schiess R, Boeni T: New vertebral and rib material point to modern bauplan of the Nariokotome Homo erectus skeleton. J Hum Evol 61:575-582, 2011

75. Hammerberg EM, Wood KB: Sagittal profile of the elderly. J Spinal Disord Tech 16:44-50, 2003

76. Han KS, Rohlmann A, Yang SJ, Kim BS, Lim TH: Spinal muscles can create compressive follower loads in the lumbar spine in a neutral standing posture. Med Eng Phys 33:472478,2011

77. Hasday CA, Passoff TL, Perry J: Gait abnormalities arising from latrogenic loss of lumbar lordosis secondary to Harrington instrumentation in lumbar fractures. Spine (Phila Pa 1976) 8:501-511, 1983

78. Hawkes K: Grandmothers and the evolution of human longevity. Am J Hum Biol 15:380-400, 2003

79. Hawkes K, O'Connell JF, Jones NGB, Alvarez H, Charnov 
EL: Grandmothering, menopause, and the evolution of human life histories. Proc Natl Acad Sci U S A 95:1336-1339, 1998

80. Hayama S, Nakatsukasa M, Kunimatsu Y: Monkey performance: the development of bipedalism in trained Japanese monkeys. Kaibogaku Zasshi 67:169-185, 1992

81. Heini PF: The current treatment-a survey of osteoporotic fracture treatment. Osteoporotic spine fractures: the spine surgeon's perspective. Osteoporos Int 16 (Suppl 2):S85S92, 2005

82. Herrington DM, Howard TD, Brosnihan KB, McDonnell DP, Li X, Hawkins GA, et al: Common estrogen receptor polymorphism augments effects of hormone replacement therapy on E-selectin but not C-reactive protein. Circulation 105:1879-1882, 2002

83. Hides J, Gilmore C, Stanton W, Bohlscheid E: Multifidus size and symmetry among chronic LBP and healthy asymptomatic subjects. Man Ther 13:43-49, 2008

84. Higgins RW, Ruff CB: The effects of distal limb segment shortening on locomotor efficiency in sloped terrain: implications for Neandertal locomotor behavior. Am J Phys Anthropol 146:336-345, 2011

85. Hirano K, Imagama S, Hasegawa Y, Muramoto A, Ishiguro N: Impact of spinal imbalance and BMI on lumbar spinal canal stenosis determined by a diagnostic support tool: cohort study in community-living people. Arch Orthop Trauma Surg 133:1477-1482, 2013

86. Hong JY, Suh SW, Modi HN, Hur CY, Song HR, Park JH: Reliability analysis for radiographic measures of lumbar lordosis in adult scoliosis: a case-control study comparing 6 methods. Eur Spine J 19:1551-1557, 2010

87. Hurwitz EL, Morgenstern H, Chiao C: Effects of recreational physical activity and back exercises on low back pain and psychological distress: findings from the UCLA Low Back Pain Study. Am J Public Health 95:1817-1824, 2005

88. Hutton WC, Malko JA, Fajman WA: Lumbar disc volume measured by MRI: effects of bed rest, horizontal exercise, and vertical loading. Aviat Space Environ Med 74:73-78, 2003

89. Hyun SJ, Rhim SC: Clinical outcomes and complications after pedicle subtraction osteotomy for fixed sagittal imbalance patients: a long-term follow-up data. J Korean Neurosurg Soc 47:95-101, 2010

90. Ianuzzi A, Kurtz SM, Kane W, Shah P, Siskey R, van Ooij A, et al: In vivo deformation, surface damage, and biostability of retrieved Dynesys systems. Spine (Phila Pa 1976) 35:E1310E1316, 2010

91. Jablonski NG, Chaplin G: Origin of habitual terrestrial bipedalism in the ancestor of the Hominidae. J Hum Evol 24:259280,1993

92. Jang JS, Lee SH, Min JH, Maeng DH: Changes in sagittal alignment after restoration of lower lumbar lordosis in patients with degenerative flat back syndrome. J Neurosurg Spine 7:387-392, 2007

93. Jang JS, Lee SH, Min JH, Maeng DH: Influence of lumbar lordosis restoration on thoracic curve and sagittal position in lumbar degenerative kyphosis patients. Spine (Phila Pa 1976) 34:280-284, 2009

94. Jones EJ, Bishop PA, Woods AK, Green JM: Cross-sectional area and muscular strength: a brief review. Sports Med 38:987-994, 2008

95. Jurmain R: Degenerative joint disease in African great apes: an evolutionary perspective. J Hum Evol 39:185-203, 2000

96. Kamaz M, Kireşi D, Oğuz H, Emlik D, Levendoğlu F: CT measurement of trunk muscle areas in patients with chronic low back pain. Diagn Interv Radiol 13:144-148, 2007

97. Kaplan H, Hill K, Lancaster J, Hurtado AM: A theory of human life history evolution: diet, intelligence, and longevity. Evol Anthropol 9:156-185, 2000

98. Kemper AR, McNally C, Duma SM: The influence of strain rate on the compressive stiffness properties of human lumbar intervertebral discs. Biomed Sci Instrum 43:176-181, 2007
99. Khan SN, Hofer MA, Gupta MC: Lumbar degenerative scoliosis: outcomes of combined anterior and posterior pelvis surgery with minimum 2-year follow-up. Orthopedics 32: 258,2009

100. Kim JH, Kim SS, Suk SI: Incidence of proximal adjacent failure in adult lumbar deformity correction based on proximal fusion level. Asian Spine J 1:19-26, 2007

101. Kim K, Kim YH: Role of trunk muscles in generating follower load in the lumbar spine of neutral standing posture. $\mathbf{J}$ Biomech Eng 130:041005, 2008

102. Kumar MN, Baklanov A, Chopin D: Correlation between sagittal plane changes and adjacent segment degeneration following lumbar spine fusion. Eur Spine J 10:314-319, 2001

103. Labelle H, Roussouly P, Berthonnaud E, Transfeldt E, O'Brien M, Chopin D, et al: Spondylolisthesis, pelvic incidence, and spinopelvic balance: a correlation study. Spine (Phila Pa 1976) 29:2049-2054, 2004

104. Lafage V, Schwab F, Patel A, Hawkinson N, Farcy JP: Pelvic tilt and truncal inclination: two key radiographic parameters in the setting of adults with spinal deformity. Spine (Phila Pa 1976) 34:E599-E606, 2009

105. Langdahl BL, Knudsen JY, Jensen HK, Gregersen N, Eriksen EF: A sequence variation: 713-8delC in the transforming growth factor-beta 1 gene has higher prevalence in osteoporotic women than in normal women and is associated with very low bone mass in osteoporotic women and increased bone turnover in both osteoporotic and normal women. Bone 20:289-294, 1997

106. Lapp MA, Bridwell KH, Lenke LG, Baldus C, Blanke K, Iffrig TM: Prospective randomization of parenteral hyperalimentation for long fusions with spinal deformity: its effect on complications and recovery from postoperative malnutrition. Spine (Phila Pa 1976) 26:809-817, 2001

107. Latimer B, Ward CV: The thoracic and lumbar vertebrae, in Walker A, Leakey R (eds): The Nariokotome Homo Erectus Skeleton. Cambridge, MA: Harvard University Press, pp 266-293, 1993

108. Ledet EH, Tymeson MP, DiRisio DJ, Cohen B, Uhl RL: Direct real-time measurement of in vivo forces in the lumbar spine. Spine J 5:85-94, 2005

109. Legaye J, Duval-Beaupère G, Hecquet J, Marty C: Pelvic incidence: a fundamental pelvic parameter for three-dimensional regulation of spinal sagittal curves. Eur Spine J 7:99-103, 1998

110. Leroux A, Fung J, Barbeau H: Postural adaptation to walking on inclined surfaces: I. Normal strategies. Gait Posture 15:64-74, 2002

111. Levine D, Colston MA, Whittle MW, Pharo EC, MarcellinLittle DJ: Sagittal lumbar spine position during standing, walking, and running at various gradients. J Athl Train 42: 29-34, 2007

112. Levine D, Whittle MW: The effects of pelvic movement on lumbar lordosis in the standing position. J Orthop Sports Phys Ther 24:130-135, 1996

113. Lieberman DE, Bramble DM: The evolution of marathon running: capabilities in humans. Sports Med 37:288-290, 2007

114. Linley SE, Peterson J, Mastropolo R, Roberts T, Lawrence $\mathrm{J}$, Glennon $\mathrm{J}$, et al: Mechanical loading rate modulates intervertebral disc trans-endplate transport. Presented at the 59th annual meeting of the Orthopaedic Research Society, San Antonio, TX, 2013 (Abstract) (http://www.ors.org/ Transactions/59/039/0230.html) [Accessed March 28, 2014]

115. Linville DA, Bridwell KH, Lenke LG, Vedantam R, Leicht P: Complications in the adult spinal deformity patient having combined surgery. Does revision increase the risk? Spine (Phila Pa 1976) 24:355-363, 1999

116. Lovejoy CO: The natural history of human gait and posture. Part 1. Spine and pelvis. Gait Posture 21:95-112, 2005

117. Lovejoy CO, McCollum MA: Spinopelvic pathways to 
bipedality: why no hominids ever relied on a bent-hip-bentknee gait. Philos Trans R Soc Lond B Biol Sci 365:32893299,2010

118. Lovejoy CO, Suwa G, Spurlock L, Asfaw B, White TD: The pelvis and femur of Ardipithecus ramidus: the emergence of upright walking. Science 326:71e1-71e6, 2009 (Erratum in Science 327:781, 2010)

119. Lowe TG, Edgar M, Margulies JY, Miller NH, Raso VJ, Reinker KA, et al: Etiology of idiopathic scoliosis: current trends in research. J Bone Joint Surg Am 82-A:1157-1168, 2000

120. Luboga S: Supernumerary lumbar vertebrae in human skeletons at the Galloway Osteological Collection of Makerere University, Kampala. East Afr Med J 77:16-19, 2000

121. Lutz JA, Otten P, Maestretti G: Late infections after dynamic stabilization of the lumbar spine with Dynesys. Eur Spine $\mathbf{J}$ 21:2573-2579, 2012

122. Maduri A, Pearson BL, Wilson SE: Lumbar-pelvic range and coordination during lifting tasks. J Electromyogr Kinesiol 18:807-814, 2008

123. Makhsous M, Lin F, Bankard J, Hendrix RW, Hepler M, Press J: Biomechanical effects of sitting with adjustable ischial and lumbar support on occupational low back pain: evaluation of sitting load and back muscle activity. BMC Musculoskelet Disord 10:17, 2009

124. Malko JA, Hutton WC, Fajman WA: An in vivo MRI study of the changes in volume (and fluid content) of the lumbar intervertebral disc after overnight bed rest and during an 8-hour walking protocol. J Spinal Disord Tech 15:157-163, 2002

125. Mangwani J, Giles C, Mullins M, Salih T, Natali C: Obesity and recovery from low back pain: a prospective study to investigate the effect of body mass index on recovery from low back pain. Ann R Coll Surg Engl 92:23-26, 2010

126. Masharawi Y, Dar G, Peleg S, Steinberg N, Medlej B, May $\mathrm{H}$, et al: A morphological adaptation of the thoracic and lumbar vertebrae to lumbar hyperlordosis in young and adult females. Eur Spine J 19:768-773, 2010

127. Masi AT, Hannon JC: Human resting muscle tone (HRMT): narrative introduction and modern concepts. J Bodyw Mov Ther 12:320-332, 2008

128. McCollum MA, Rosenman BA, Suwa G, Meindl RS, Lovejoy CO: The vertebral formula of the last common ancestor of African apes and humans. J Exp Zoolog B Mol Dev Evol 314:123-134, 2010

129. McDonnell MF, Glassman SD, Dimar JR II, Puno RM, Johnson JR: Perioperative complications of anterior procedures on the spine. J Bone Joint Surg Am 78:839-847, 1996

130. Meakin JR, Aspden RM: Modeling the effect of variation in sagittal curvature on the force required to produce a follower load in the lumbar spine. J Mech Med Biol 12:1250013, 2012

131. Meakin JR, Fulford J, Seymour R, Welsman JR, Knapp KM: The relationship between sagittal curvature and extensor muscle volume in the lumbar spine. J Anat 222:608-614, 2013

132. Meakin JR, Gregory JS, Aspden RM, Smith FW, Gilbert FJ: The intrinsic shape of the human lumbar spine in the supine, standing and sitting postures: characterization using an active shape model. J Anat 215:206-211, 2009

133. Melton LJ III, Thamer M, Ray NF, Chan JK, Chesnut CH III, Einhorn TA, et al: Fractures attributable to osteoporosis: report from the National Osteoporosis Foundation. J Bone Miner Res 12:16-23, 1997

134. Mitchell T, O'Sullivan PB, Burnett AF, Straker L, Smith A: Regional differences in lumbar spinal posture and the influence of low back pain. BMC Musculoskelet Disord 9: 152,2008

135. Moreside JM, McGill SM: How do elliptical machines differ from walking: a study of torso motion and muscle activity. Clin Biomech (Bristol, Avon) 27:738-743, 2012

136. Mörl F, Bradl I: Lumbar posture and muscular activity while sitting during office work. J Electromyogr Kinesiol 23: 362-368, 2013

137. Murrie VL, Dixon AK, Hollingworth W, Wilson H, Doyle TA: Lumbar lordosis: study of patients with and without low back pain. Clin Anat 16:144-147, 2003

138. Niosi CA, Oxland TR: Degenerative mechanics of the lumbar spine. Spine J 4 (6 Suppl):202S-208S, 2004

139. Norton BJ, Sahrmann SA, Van Dillen FL: Differences in measurements of lumbar curvature related to gender and low back pain. J Orthop Sports Phys Ther 34:524-534, 2004

140. Nuckley DJ, Kramer PA, Del Rosario A, Fabro N, Baran $S$, Ching RP: Intervertebral disc degeneration in a naturally occurring primate model: radiographic and biomechanical evidence. J Orthop Res 26:1283-1288, 2008

141. O'Brien MF, Kuklo TR, Blanke KM, Lenke LG: Spinal Deformity Study Group Radiographic Measurement Manual. Memphis, TN: Medtronic Sofamor Danek, 2004, p 110

142. O'Connell JF, Hawkes K, Blurton Jones NG: Grandmothering and the evolution of homo erectus. J Hum Evol 36:461-485, 1999

143. Ostrowska B, Rozek-Mróz K, Giemza C: Body posture in elderly, physically active males. Aging Male 6:222-229, 2003

144. Paajanen H, Lehto I, Alanen A, Erkintalo M, Komu M: Diurnal fluid changes of lumbar discs measured indirectly by magnetic resonance imaging. J Orthop Res 12:509-514, 1994

145. Patwardhan AG, Havey RM, Meade KP, Lee B, Dunlap B: A follower load increases the load-carrying capacity of the lumbar spine in compression. Spine (Phila Pa 1976) 24: 1003-1009, 1999

146. Peccei JS: A critique of the grandmother hypotheses: old and new. Am J Hum Biol 13:434-452, 2001

147. Peleg S, Dar G, Medlej B, Steinberg N, Masharawi Y, Latimer B, et al: Orientation of the human sacrum: anthropological perspectives and methodological approaches. Am J Phys Anthropol 133:967-977, 2007

148. Ploumis A, Simpson AK, Cha TD, Herzog JP, Wood KB: Coronal spinal balance in adult spine deformity patients with long spinal fusions: a minimum 2-5 year follow-up study. J Spinal Disord Tech [epub ahead of print], 2013

149. Pocock NA, Eisman JA, Hopper JL, Yeates MG, Sambrook PN, Eberl S: Genetic determinants of bone mass in adults. A twin study. J Clin Invest 80:706-710, 1987

150. Pollintine P, Przybyla AS, Dolan P, Adams MA: Neural arch load-bearing in old and degenerated spines. J Biomech 37:197-204, 2004

151. Preuschoft H, Hayama S, Günther MM: Curvature of the lumbar spine as a consequence of mechanical necessities in Japanese macaques trained for bipedalism. Folia Primatol (Basel) 50:42-58, 1988

152. Proietti L, Scaramuzzo L, Schiro' GR, Sessa S, Logroscino CA: Complications in lumbar spine surgery: a retrospective analysis. Indian J Orthop 47:340-345, 2013

153. Ralston SH: Genetics of osteoporosis. Proc Nutr Soc 66: 158-165, 2007

154. Reno PL, DeGusta D, Serrat MA, Meindl RS, White TD, Eckhardt RB, et al: Plio-pleistocene hominid limb proportions: evolutionary reversals or estimation errors? Curr Anthropol 46:575-588, 2005

155. Richmond BG, Aiello LC, Wood BA: Early hominin limb proportions. J Hum Evol 43:529-548, 2002

156. Roberts N, Hogg D, Whitehouse GH, Dangerfield P: Quantitative analysis of diurnal variation in volume and water content of lumbar intervertebral discs. Clin Anat 11:1-8, 1998

157. Robinson JT: Early Hominid Posture and Locomotion. Chicago: University of Chicago Press, 1972

158. Rogers J, Watt I, Dieppe P: Palaeopathology of spinal osteo- 
phytosis, vertebral ankylosis, ankylosing spondylitis, and vertebral hyperostosis. Ann Rheum Dis 44:113-120, 1985

159. Romero-Vargas S, Zárate-Kalfópulos B, Otero-Cámara E, Rosales-Olivarez L, Alpízar-Aguirre A, Morales-Hernández E, et al: The impact of body mass index and central obesity on the spino-pelvic parameters: a correlation study. Eur Spine J 22:878-882, 2013

160. Rosenman B: Triangulating the Evolution of the Vertebral Column in the Last Common Ancestor: Thoracolumbar Transverse Process Homology in the Hominoidea [dissertation]. Kent, OH: Kent State University, 2008

161. Roussouly P, Nnadi C: Sagittal plane deformity: an overview of interpretation and management. Eur Spine J 19:18241836, 2010

162. Ruff CB: Biomechanics of the hip and birth in early Homo. Am J Phys Anthropol 98:527-574, 1995

163. Saha D, Gard S, Fatone S: The effect of trunk flexion on able-bodied gait. Gait Posture 27:653-660, 2008

164. Saha D, Gard S, Fatone S, Ondra S: The effect of trunkflexed postures on balance and metabolic energy expenditure during standing. Spine (Phila Pa 1976) 32:1605-1611, 2007

165. Sambrook PN, MacGregor AJ, Spector TD: Genetic influences on cervical and lumbar disc degeneration: a magnetic resonance imaging study in twins. Arthritis Rheum 42: 366-372, 1999

166. Sanders WJ: Comparative morphometric study of the australopithecine vertebral series Stw-H8/H41. J Hum Evol 34: 249-302, 1998

167. Scannell JP, McGill SM: Lumbar posture-should it, and can it, be modified? A study of passive tissue stiffness and lumbar position during activities of daily living. Phys Ther 83:907-917, 2003

168. Schache AG, Bennell KL, Blanch PD, Wrigley TV: The coordinated movement of the lumbo-pelvic-hip complex during running: a literature review. Gait Posture 10:30-47, 1999

169. Schache AG, Blanch P, Rath D, Wrigley T, Bennell K: Three-dimensional angular kinematics of the lumbar spine and pelvis during running. Hum Mov Sci 21:273-293, 2002

170. Schwab F, Farcy JP, Bridwell K, Berven S, Glassman S, Harrast J, et al: A clinical impact classification of scoliosis in the adult. Spine (Phila Pa 1976) 31:2109-2114, 2006

171. Schwab F, Lafage V, Patel A, Farcy JP: Sagittal plane considerations and the pelvis in the adult patient. Spine (Phila Pa 1976) 34:1828-1833, 2009

172. Schwab F, Patel A, Ungar B, Farcy JP, Lafage V: Adult spinal deformity-postoperative standing imbalance: how much can you tolerate? An overview of key parameters in assessing alignment and planning corrective surgery. Spine (Phila Pa 1976) 35:2224-2231, 2010

173. Schwab F, Ungar B, Blondel B, Buchowski J, Coe J, Deinlein D, et al: Scoliosis Research Society-Schwab adult spinal deformity classification: a validation study. Spine (Phila Pa 1976) 37:1077-1082, 2012

174. Schwab FJ, Blondel B, Bess S, Hostin R, Shaffrey CI, Smith JS, et al: Radiographical spinopelvic parameters and disability in the setting of adult spinal deformity: a prospective multicenter analysis. Spine (Phila Pa 1976) 38:E803-E812, 2013

175. Senut B, Pickford M, Gommery D, Mein P, Cheboi K, Coppens Y: First hominid from the Miocene (Lukeino Formation, Kenya). C R Acad Sci Sâer II Sci Terre Planáetes 332:137-144, 2001

176. Setton LA, Chen J: Mechanobiology of the intervertebral disc and relevance to disc degeneration. J Bone Joint Surg Am 88 (Suppl 2):52-57, 2006

177. Sibley CG, Ahlquist JE: DNA hybridization evidence of hominoid phylogeny: results from an expanded data set. J Mol Evol 26:99-121, 1987
178. Sinaki M, Itoi E, Rogers JW, Bergstralh EJ, Wahner HW: Correlation of back extensor strength with thoracic kyphosis and lumbar lordosis in estrogen-deficient women. Am J Phys Med Rehabil 75:370-374, 1996

179. Smith DM, Nance WE, Kang KW, Christian JC, Johnston CC Jr: Genetic factors in determining bone mass. J Clin Invest 52:2800-2808, 1973

180. Smith JS, Shaffrey CI, Berven S, Glassman S, Hamill C, Horton W, et al: Improvement of back pain with operative and nonoperative treatment in adults with scoliosis. Neurosurgery 65:86-94, 2009

181. Smith JS, Shaffrey CI, Berven S, Glassman S, Hamill C, Horton W, et al: Operative versus nonoperative treatment of leg pain in adults with scoliosis: a retrospective review of a prospective multicenter database with two-year follow-up. Spine (Phila Pa 1976) 34:1693-1698, 2009

182. Sobacchi C, Vezzoni P, Reid DM, McGuigan FE, Frattini A, Mirolo M, et al: Association between a polymorphism affecting an AP1 binding site in the promoter of the TCIRG1 gene and bone mass in women. Calcif Tissue Int 74:35-41, 2004

183. Sockol MD, Raichlen DA, Pontzer H: Chimpanzee locomotor energetics and the origin of human bipedalism. Proc Natl Acad Sci U S A 104:12265-12269, 2007

184. Stokes IA, Iatridis JC: Mechanical conditions that accelerate intervertebral disc degeneration: overload versus immobilization. Spine (Phila Pa 1976) 29:2724-2732, 2004

185. Takeda N, Kobayashi T, Atsuta Y, Matsuno T, Shirado O, Minami A: Changes in the sagittal spinal alignment of the elderly without vertebral fractures: a minimum 10-year longitudinal study. J Orthop Sci 14:748-753, 2009

186. Takemitsu Y, Harada Y, Iwahara T, Miyamoto M, Miyatake Y: Lumbar degenerative kyphosis. Clinical, radiological and epidemiological studies. Spine (Phila Pa 1976) 13:13171326,1988

187. Terran J, Schwab F, Shaffrey CI, Smith JS, Devos P, Ames $\mathrm{CP}$, et al: The SRS-Schwab adult spinal deformity classification: assessment and clinical correlations based on a prospective operative and nonoperative cohort. Neurosurgery 73:559-568, 2013

188. Thakkinstian A, D'Este C, Eisman J, Nguyen T, Attia J: Meta-analysis of molecular association studies: vitamin D receptor gene polymorphisms and BMD as a case study. $\mathbf{J}$ Bone Miner Res 19:419-428, 2004

189. Toussaint M, Macho GA, Tobias PV, Partridge TC, Hughes AR: The third partial skeleton of a late Pliocene hominin (Stw 431) from Sterkfontein, South Africa. S Afr J Sci 99: 215-223, 2003

190. Uitterlinden AG, Arp PP, Paeper BW, Charmley P, Proll $\mathrm{S}$, Rivadeneira F, et al: Polymorphisms in the sclerosteosis/ van Buchem disease gene (SOST) region are associated with bone-mineral density in elderly whites. Am J Hum Genet 75:1032-1045, 2004

191. Urban JP, Smith S, Fairbank JC: Nutrition of the intervertebral disc. Spine (Phila Pa 1976) 29:2700-2709, 2004

192. Urban MK, Jules-Elysee KM, Beckman JB, Sivjee K, King $\mathrm{T}$, Kelsey W, et al: Pulmonary injury in patients undergoing complex spine surgery. Spine J 5:269-276, 2005

193. van Deursen LL, van Deursen DL, Snijders CJ, Wilke HJ: Relationship between everyday activities and spinal shrinkage. Clin Biomech (Bristol, Avon) 20:547-550, 2005

194. Vialle R, Levassor N, Rillardon L, Templier A, Skalli W, Guigui P: Radiographic analysis of the sagittal alignment and balance of the spine in asymptomatic subjects. J Bone Joint Surg Am 87:260-267, 2005

195. Videman T, Leppävuori J, Kaprio J, Battié MC, Gibbons LE, Peltonen L, et al: Intragenic polymorphisms of the vitamin D receptor gene associated with intervertebral disc degeneration. Spine (Phila Pa 1976) 23:2477-2485, 1998

196. Videman T, Levälahti E, Battié MC: The effects of anthro- 


\section{J. Sparrey et al.}

pometrics, lifting strength, and physical activities in disc degeneration. Spine (Phila Pa 1976) 32:1406-1413, 2007

197. Vogt L, Banzer W: Measurement of lumbar spine kinematics in incline treadmill walking. Gait Posture 9:18-23, 1999

198. Wallwork TL, Stanton WR, Freke M, Hides JA: The effect of chronic low back pain on size and contraction of the lumbar multifidus muscle. Man Ther 14:496-500, 2009

199. Wang DL, Jiang SD, Dai LY: Biologic response of the intervertebral disc to static and dynamic compression in vitro. Spine (Phila Pa 1976) 32:2521-2528, 2007

200. Ward CV: Interpreting the posture and locomotion of Australopithecus afarensis: where do we stand? Am J Phys Anthropol 119 (Suppl 35): 185-215, 2002

201. Ward CV: Torso morphology and locomotion in Proconsul nyanzae. Am J Phys Anthropol 92:291-328, 1993

202. Weber J, Pusch CM: The lumbar spine in Neanderthals shows natural kyphosis. Eur Spine J 17 (Suppl 2):S327-S330, 2008

203. Whitcome KK: Functional implications of variation in lumbar vertebral count among hominins. J Hum Evol 62:486-497, 2012

204. Whitcome KK, Shapiro LJ, Lieberman DE: Fetal load and the evolution of lumbar lordosis in bipedal hominins. Nature 450:1075-1078, 2007

205. Whittle MW, Levine D: Three-dimensional relationships between the movements of the pelvis and lumbar spine during normal gait. Hum Mov Sci 18:681-692, 1999

206. Williams GC, Nesse RM: The dawn of Darwinian medicine. Q Rev Biol 66: 1-22, 1991
207. Williams SA, Ostrofsky KR, Frater N, Churchill SE, Schmid P, Berger LR: The vertebral column of Australopithecus sediba. Science 340:1232996, 2013

208. Woolston SL, Beukelman T, Sherry DD: Back mobility and interincisor distance ranges in racially diverse North American healthy children and relationship to generalized hypermobility. Pediatr Rheumatol Online J 10:17, 2012

209. World Health Organization: Assessment of fracture risk and its application to screening for postmenopausal osteoporosis. Report of a WHO Study Group. World Health Organ Tech Rep Ser 843:1-129, 1994

210. Youdas JW, Garrett TR, Harmsen S, Suman VJ, Carey JR: Lumbar lordosis and pelvic inclination of asymptomatic adults. Phys Ther 76:1066-1081, 1996

211. Youdas JW, Hollman JH, Krause DA: The effects of gender, age, and body mass index on standing lumbar curvature in persons without current low back pain. Physiother Theory Pract 22:229-237, 2006

Manuscript submitted December 5, 2013.

Accepted January 24, 2014.

Please include this information when citing this paper: DOI: 10.3171/2014.1.FOCUS13551.

Address correspondence to: Carolyn J. Sparrey, Ph.D., Simon Fraser University, 250-13450 102 Ave., Surrey, BC, Canada V3T 0A3.email: csparrey@sfu.ca. 